\title{
ALCALDES Y MAYORDOMOS: LIDERAZGO INDÍGENA EN EL CONTEXTO ANDINO Y COLONIAL (DOCTRINA DE BELÉN, 1782-1813)
}

\author{
ALCALDES AND MAYORDOMOS: INDIGENOUS LEADERSHIP IN THE \\ ANDEAN AND COLONIAL CONTEXT (DOCTRINA DE BELENN, 1782-1813)
}

\author{
Xochitl Inostroza Ponce ${ }^{1}$ y Jorge Hidalgo Lehuedé
}

\begin{abstract}
Como han demostrado diversos estudios, los procesos que se desarrollaron en la zona andina a fines del periodo Colonial provocaron el debilitamiento de la figura del cacique en diversas localidades. En los Altos de Arica, la documentación eclesiástica de la doctrina de Belén, evidencia que junto con el desprestigio de la autoridad cacical se experimentó un fortalecimiento de las autoridades del cabildo indígena, cuyos integrantes no solo cumplieron roles políticos, sino que también desempeñaron funciones religiosas. Nos proponemos poner en evidencia la gran cantidad de autoridades locales que se suceden en cargos entre 1782 y 1813 en la doctrina de Belén, para luego, esbozar los distintos aspectos sociales, religiosos y económicos que rodearon a las autoridades de los pueblos de Belén -cabecera de la doctrina- y Socoroma, intentando comprender los antecedentes y alcances de su prestigio y sus particularidades con respecto a otros liderazgos indígenas del periodo Colonial. Finalmente, hacemos una propuesta alternativa al concepto de mediadores culturales, entendiendo a estas autoridades étnicas no como "mediadores", sino como sujetos relacionales.
\end{abstract}

Palabras claves: cabildo, cofradías, sistema de cargos, mediadores, compadrazgo, redes sociales.

As several studies have shown, the processes that developed in the Andean area towards the end of the colonial period weakened the cacique figure in several localities. In the highlands of Arica, the ecclesiastical documentation of the Doctrine of Belén shows that the loss of the cacique's authority contrasted with a strengthening of the indigenous chapter, the members of which fulfilled not only political roles, but also religious functions. This article highlights the high number of local authorities that succeeded one another in the Doctrine of Belén between 1782 and 1813, and outlines the various social, religious, and economic aspects that surrounded the authorities of the towns of Belén, head of the doctrine, and Socoroma, so as to understand the origin and scope of their prestige, as well as their peculiarities with respect to other indigenous leaders of the colonial period. Finally, we make an alternative proposal to the concept of cultural mediators by regarding them as ethnic authorities acting as relational subjects.

Key words: Cabildo, confraternities, system of charges, mediators, godfatherhood, social networks.

\section{Curacas, Alcaldes y Cabildo Indígena}

Desde el sistema de curacas, líderes étnicos que interactuaban con la estructura política, religiosa, militar y económica de los Incas en los Andes, hasta las transformaciones coloniales por influencia hispana o por la agencia de los propios andinos, se organiza una historia compleja de mitos, continuidades, rupturas, adaptaciones e invenciones. En el inicio de la colonia los títulos de encomiendas permiten apreciar como los conquistadores europeos utilizaron los sistemas políticos locales para controlar los territorios y sus habitantes, así como, principalmente, extraer los excedentes que sostenían a las nuevas elites europeas (Trellez 1982). Los caciques legitimados por el sistema colonial, denominados curacas en los Andes, fueron repartidos entre los encomenderos con un determinado número de indios o varones en edad de trabajar. Sin un conocimiento de las lenguas nativas el uso de estos intermediarios fue indispensable para movilizar y transformar a las masas indígenas. Más que un problema de idioma era uno de incompatibilidad de términos, de culturas económicas, políticas y religiosas que tenían siglos de desarrollo diferenciado, por más que hubiera

\footnotetext{
${ }^{1}$ Centro de Estudios Culturales Latinoamericanos, Universidad de Chile, Santiago, Chile. xochitl@uchile.cl

2 Departamento de Ciencias Históricas, Universidad de Chile, Santiago, Chile. hidalgol@uchile.cl
}

Recibido: agosto 2019. Aceptado: febrero 2020.

http://dx.doi.org/10.4067/S0717-73562021005000402. Publicado en línea: 10-abril-2021. 
algunas coincidencias. Los doctrineros contratados por los titulares de las encomiendas se volcaron a evangelizar masivamente y superficialmente a los nuevos súbditos y, en muchos casos, a destruir los santuarios o mochaderos. Se pensaba que si se evangelizaba a los curacas se facilitaría la evangelización, pero como se ha demostrado, algunos curacas necesitaban recrear cultos, costumbre y discursos para legitimarse ante sus propios indios en ritos en que se invocaba a las huacas para lograr la germinación de la vida y la reproducción social (Millones 1978, 1979, 1984; Salomon 1987; Marsilli 2014). Sin embargo, se debe reconocer que los caciques presentaron una "amplia variedad de trayectorias" (Morrone 2016), donde el poder político local mantuvo vinculaciones con la órbita religiosa y administrativa (Escobari 2001; Mendinacelli e Inch 2010; O'Phelan 2013; Platt et. al. 2006; entre otros).

La Corona, directamente o por medio de la Audiencia de Lima, procuró limitar el poder de los caciques en sus atribuciones judiciales aunque se les reconoció el derecho a gobernar sobre su jurisdicción. La justificación fue evitar que abusaran de los indios comunes. Así, la Audiencia de Lima en 1551 limitó la jurisdicción criminal de los curacas, prohibiéndoles la aplicación de la pena de muerte o de mutilación. La poliginia les quedó prohibida, así como el excesivo número de sirvientes y séquito. Estas disposiciones fueron vistas como una humillación por los curacas así como una reducción de su estatus, pues parte de su tradicional prestigio residía en rodearse de un numeroso cortejo de seguidores, hombres y mujeres (Espinoza 1960:202). Por otra parte, las relaciones mercantiles y el uso indiscriminado de la mano de obra indígena hacía difícil que las normas tradicionales de reciprocidad y redistribución se conservaran como en los tiempos prehispánicos (Murra 1975; Pease 1992). Había sin duda mayor violencia y una extracción de recursos de las propias chacras de los tributarios, que anteriormente se había limitado solo a turnos de trabajo en las tierras del Inca, del curaca o de la huaca (Wachtel 1973, 1976).

Otra manera de quitarle el monopolio de la autoridad a los líderes locales fue la creación de los cabildos de indios, fundados sobre el modelo hispano, como se aprecia en la nominación de los cargos: alcaldes, regidores, alguaciles, fiscales. Para ello fue necesario reestructurar el sistema de asentamiento disperso por otro reducido en pueblos. Aun cuando el proceso venía de antes, es con el gobierno del Virrey Toledo (15691581) y su visita del territorio que se acelera y masifica (Hidalgo 1986). El gobierno municipal fue entregado al cabildo, intentando mermar el poder de los caciques, donde los alcaldes cumplieron varias de las funciones antiguamente entregadas a los curacas (Zuloaga 2012), tales como reparto de tierras comunitarias y el manejo de tareas colectivas como la conservación de puentes y caminos, reparación de los tambos, el cuidado de los huérfanos y de nuevas instituciones como la cárcel, el hospital y el mercado (Marzal 1983:79-81). Según Spalding, los alcaldes administraban justicia en los pueblos desde las ordenanzas de Toledo (1984:216), pero sus atribuciones estaban limitadas en aquellos casos que exigían pena de muerte o mutilación de miembro (Espinoza 1960:23). A ellos se sumaban los ayudantes de la iglesia que también quedaban excluidos del pago de tributo que cancelaban los del común. Se creaba así, en estos pueblos organizados como dameros, la República de los Indios, con cargos que se renovaban anualmente y donde se establecía una clara jerarquía entre sus integrantes.

Estas características generales se desarrollaron de distinta manera en diferentes lugares. En algunos casos los curacas compartieron sus funciones con los alcaldes mayores y los regidores. Mayoritariamente, el curaca siguió siendo la voz de la gente, pero en algunos lugares los deberes y el poder del alcalde mayor eclipsó al curaca y en otros lo reemplazó completamente (Spalding 1974:74). Según Espinoza (1975:378) el cargo de alcalde mayor, un oficio vitalicio, recaía en un curaca perteneciente a la más alta aristocracia nativa, ubicado en la posición superior dentro del sistema colonial hispano. Lavallé (1993) en cambio, propone que el alcalde varayoc, desde la constitución de la "república de indios" era elegido por el común, siguiendo la tradición castellana aunque en hibridación con antiguos sistemas de autoridades indígenas (Chassin 2008:229). Esta propuesta a nuestro juicio es muy discutible, pues gran parte de la evidencia sugiere que el cargo era otorgado por la administración colonial (ver p.ej., Saignes 1987). En el contexto de Nueva España, en los primeros siglos de la época colonial, se observan casos en que los miembros del cabildo eran electos, pero los candidatos correspondían a nobles o principales (Mendoza 2011:47-48). Espinoza propone que el cargo de Alcalde Mayor se reservaba para aquellos notoriamente fieles al Rey, que supieran leer y escribir, conocieran las leyes, fueran cristianos practicantes, capaces de administrar la justicia civil y criminal, hablaran bien español y se vistieran a la usanza de un hispano. Participaba en funciones civiles y religiosas, entre ellas, supervisar que los indios asistieran a misa y recibieran los sacramentos. Administrativamente recolectaba tributos, reclutaba mitayos y otros sujetos que prestaban diversos servicios. No obstante, tal modelo no lo encontramos en el área de los corregimientos de Arica, Tarapacá y Atacama (Hidalgo 1986:48-50). En cambio, en los títulos que recibían los caciques se establecían varias de estas funciones. Es decir, en nuestra área de estudio el cargo de cacique fue apoyado por las autoridades hispanas y fue un motivo de constante preocupación en cada una 
de las doctrinas que coincidían generalmente con un cacicazgo, lo que se observa en las disputas de sucesión de los mismos (Hidalgo 1986:58-111). Aun así, existían los cabildos indígenas y el concepto de indios nobles o principales en cada comunidad.

La situación cambió a fines del siglo XVIII, en parte debido a las políticas borbónicas gatilladas por las repercusiones de la Rebelión de Tupac Amaru y Tupac Catari (Hünefeldt 1982; O'Phelan 1977; 1992, 1997; Palomeque 1998) que provocaron una reestructuración del sistema de autoridades étnicas, de manera también diferenciada, pues, mientras en algunas localidades la importancia del cacique se mantuvo, en otras decayó o desapareció, potenciándose los cargos del cabildo a nivel local (Chassin 2008; Choque 2003; Hidalgo 1986; Inostroza 2011, 2019; O'Phelan 1997; Palomeque 2006; Peralta 1991; Rivera Cusicanqui 1978; Vicent 2015; Walker 2013; entre otros). Lo mismo ocurrió con la figura del alcalde mayor, posicionándose tanto a nivel de provincias por sobre los caciques locales, o a nivel de pueblos subalternos a éstos. Sala i Vila propone que, aunque Lohmann Villena (1957) identifica al cabildo de indios en Lima y Cusco bajo la administración de los Austrias, esta institución se fortaleció y masificó a fines del siglo XVIII, momento en el cual se provocó "... un lento cambio en la dirigencia comunal en el que el cabildo y los alcaldes indígenas asumieron el control y defensa de los intereses del común en detrimento de los caciques" (Sala i Vila 1996:152). En otro trabajo la autora menciona que los alcaldes debían contar con la aprobación de curas, subdelegados e intendentes, pues de lo contrario ellos anulaban su elección. Indica además que en algunas localidades las comunidades se subordinaron a un alcalde no indígena, aunque este aspecto no se evidencia en Cusco, Puno, La Paz y en la zona de Charcas (Sala i Vila 1993:55, 57).

En varias localidades se ha observado el tránsito hacia un sistema que integró a caciques y alcaldes (Boixadós 2008; Fabermann 2004 y 2008; Farberman y Boixadós 2009; Rodríguez 2017), mencionándose algunos posibles factores que pudieron incidir en la imbricación de los roles de las autoridades de Tucumán y Santiago del Estero: aumento demográfico, cambios en el sistema de encomienda, además de las políticas de la nueva dinastía (Rodríguez 2017:18). En este sentido, el aporte de la presente investigación está en dar cuenta de la situación opuesta, en un escenario donde el cacique pierde relevancia, lo que por lo tanto, permite explicar el fundamento de los liderazgos locales emergentes.

Finalmente, el proceso de Independencia habría modificado este sistema, lo que se inicia con la ley municipal de las Cortes de Cádiz (1812-1813) que conformó un ayuntamiento integrado por españoles, mestizos e indios (Sala i Vila 1996:152). Palomeque identifica este organismo como Cabildos Constitucionales
(1998:42), emergentes desde el decreto de Bolívar del 15 de octubre de 1812, a partir del cual los cabildos de indígenas fueron reemplazados por cabildos pequeños con funciones similares, aunque más limitadas (Palomeque 2000:128).

En Nueva España se observa un proceso similar, tanto en la multiplicidad de cargos civiles y religiosos (siempre en estrecha relación), como en el proceso de "recuperación étnica" de las autoridades locales que habría tenido lugar en la segunda mitad del siglo XVIII (Carmagnani 1988). De igual manera, se observa en algunas localidades la decadencia que experimentó la figura del cacique, aunque siguió ostentando cierto poder simbólico (Yannakakis 2012), y paralelamente el desarrollo de mayor autonomía en algunos pueblos indígenas a partir de la Constitución de Cádiz de 1812 (Mendoza 2011).

\section{Autoridades Étnicas y Dimensión Religiosa}

Desde sus orígenes la política hispana en América buscó disciplinar a los habitantes conquistados para ponerlos al servicio de las dos majestades: Dios y el Rey. Es decir, ponerlos bajo la tuición de la iglesia y del poder político civil. Existía una estrecha relación entre la monarquía hispana y la iglesia en el nuevo continente, de manera que a veces sus funciones e intereses se sobreponían. La Monarquía por medio del Patronato Real designaba a los obispos y éstos a los párrocos, cuyo sínodo era pagado por la recolección fiscal del tributo, del mismo modo que los diezmos. La iglesia asumía funciones de educación, salud pública y el registro de sacramentos, principalmente bautismos, matrimonios y defunciones (Marzal 1983:77).

Marzal (1983) considera que la cristianización del Perú comprendió tres fases: evangelización intensiva (siglo XVI), reevangelización o extirpación de idolatrías (primera mitad del siglo XVII) y la cristalización del nuevo sistema (segunda mitad del siglo XVII). En nuestra zona de estudio aún falta investigación que permita establecer las fases de la periodización de Marzal; aunque en el caso de Atacama podría haber mayor coincidencia, en cambio en Arica y Tarapacá no se ha detectado lo que se llama propiamente campañas de extirpación, aunque hay rasgos presentes de forma aislada (Castro 2009; Hidalgo 2011; Hidalgo y Díaz 1985; Hidalgo et al. 2014; 2016; Horta et al. 2016; Marsilli y Cisternas 2010; Núñez y Castro 2011). La cristalización en Arica parece también algo atrasada a juzgar por los informes eclesiásticos (Hidalgo 1986:5253), observándose en la segunda mitad del siglo XVIII (Inostroza 2018b, 2019).

Los españoles iniciaron sus actividades misionales en América justamente en los tiempos que la reforma protestante propiciaba el retorno a las fuentes originales 
del cristianismo, condenando los excesos de la piedad popular, suprimiendo el culto a los santos y reduciendo los siete sacramentos a solo dos: bautismo y comunión. Los misioneros, por el contrario, siguiendo las tradiciones hispanas, van a enfatizar los rituales (ciclo litúrgico o el recuerdo de la vida de Cristo durante el año), el culto a los santos o el ciclo santoral con sus múltiples fiestas y todos los sacramentos. La devoción a los santos, como intermediarios en la comunicación con Dios, adquirió gran importancia en la gente andina, llegando a ser uno de los más significativos ritos de la andinización del cristianismo (Marzal 1983:262-263). Hay diversas evidencias de sujetos indígenas en los Andes que solicitan ser dotados de sacerdotes para que los atendieran en lugares aislados donde esperaban poder escuchar misas. Por ejemplo, en el caso de Susques en Atacama, a pesar de tener capilla instalada en 1757, los feligreses temían de no poder confesarse, y en el fatídico destino de sus almas si morían sin recibir los ritos de los moribundos (Hidalgo 1986:55). También en los Altos de Arica, hacia 1748 las autoridades de Socoroma se quejaron del cura Pedro Caseres por "tantos y tan públicos agravios", siendo el principal el no administrarles sacramentos ${ }^{1}$.

El culto a entidades religiosas cristianas se asocia con el sistema de cargos, un régimen de turnos anuales donde una familia o individuo asume la responsabilidad de las fiestas cúlticas y su financiamiento. La fiesta incluía diversos gastos, bebidas y alimentos para los asistentes, especialmente chicha y vino, velas, incienso, fuegos artificiales, bandas, gastos del cura, etc. En el sistema político-religioso de los campesinos coloniales indígenas de Mesoamérica y los Andes, las funciones religiosas asumidas por individuos podían empobrecerlos por años, pero el prestigio ganado era muy alto a los ojos del resto de su comunidad. Un hombre anciano podía haber completado el paso de sus obligaciones religiosas varias vecesen su vida, y producto de ello se había ganado el respeto y admiración de los comuneros, aun cuando podría haber terminado en la pobreza material (Wolf 1959:193). En el modelo de Wolf, este sistema religioso fue el principal instrumento para que un hombre o familia ganara prestigio, y al mismo tiempo se aseguraba el equilibrio económico de la comunidad por medio de la obligación de sus miembros de gastar sus excedentes en festividades colectivas, creando momentos mágicos de arte y belleza en que se mezclan los ritos religiosos y la embriaguez. Este proceso nivelaba las diferencias de riqueza y prevenía el establecimiento de clases económicas en una comunidad de desposeídos. Para Wolf, la conducta religiosa y política fueron mutuamente dependientes; la participación en el sistema religioso calificaba a un hombre para un rol similar en el sistema político (Wolf 1959:194-195). El autor citado ubica el nacimiento de este sistema en el siglo XVII en Mesoamérica, justamente cuando se expande la hacienda y los campesinos indígenas son relegados a tierras de refugio, donde el desequilibrio económico podría amenazar la subsistencia mayoritaria. Reconoce también que el sistema se deriva de la tradición ibérica de cofradías y fraternidades religiosas, que eran "asociaciones voluntarias de hombres con fines religiosos", pero también tenía orígenes prehispánicos, citando como prueba el relato del monje Toribio de Benavente, quien describe que antes de la conquista hubo hombres que ahorraron por años "con el fin de honrar al Diablo con una festividad", quedando endeudados después de ello (Wolf 1959:193-194).

El origen del sistema de cargos (Korsbaek 1995; Topete 2014) es complejo debido a la carencia de suficientes pruebas en los cronistas tempranos. Si bien se pueden detectar elementos aislados, éstos están lejos de constituir un sistema, integrado y muy diverso como el que ha establecido la investigación moderna, en particular a partir de los aportes antropológicos contemporáneos (Korbaek 1995:177-178). Platt ha llamado la atención en cuanto a que el calendario litúrgico de las fiestas entre los macha fue un eficiente sistema de evangelización basado en cofradías, aun cuando elementos prehispánicos han seguido aflorando hasta la actualidad, como la adoración al sol, en aparente culto de Dios, como una síntesis cósmica realizada por el cristianismo andino (Platt 1987).

En el caso de Arica tenemos un testimonio del ex corregidor Demetrio Egan (1770-1775), quien en 1778 emitió un dictamen sobre los repartos de mercancías o venta forzada que hacían los corregidores a los indígenas que, de acuerdo con numerosas acusaciones y demandas, se entregaban en cantidades y precios superiores a los autorizados en los aranceles aprobados por el Virrey, desde 1750-1756. Egan alegaba que estos repartos eran necesarios como un crédito a indios pobres, flojos, miserables y adictos a embriagarse. Los que se oponían al reparto tenían sus propios intereses, entre ellos los curas que impulsaban las múltiples fiestas a los santos en las iglesias. Los días de fiesta eran organizados y financiados por indios alférez que pagaban todos los gastos de las misas, comidas, fuegos artificiales y la mantención del sacerdote por ocho días. En esas ocasiones la embriaguez era continua. Egan concluía que, si aun los indios trabajaban felizmente todo el año, ellos no podrían ganar lo suficiente para pagar por esos festivales (Hidalgo 1986:55). Es evidente que para la población andina estas celebraciones cumplían un papel importante en la conservación de unidades políticas y religiosas, que en la observación ilustrada e interesada del ex corregidor no fueron apreciadas.

En cuanto a las cofradías, hay evidencia en los Altos de Arica sobre los mecanismos mediante los 
cuales funcionaron para los siglos XVII y XIX (Díaz et al. 2014), con un aparente receso de sus funciones durante el siglo XVIII, y revitalizados, a nuestro juicio, por el cura Mariano Pacheco de Peñaloza (1778-1808) a partir de la restitución de cargos (Inostroza 2018b) ${ }^{2}$.

\section{Autoridades Indígenas en el Periodo Tardocolonial: Altos de Arica}

Los procesos de constitución y desarrollo de los cacicazgos en el área del norte de Chile en general, y del corregimiento de Arica en particular, han sido abordados anteriormente (Hidalgo 1986, 2004 [1987]; Hidalgo y Castro 2004; Hidalgo y Durston 2004 [1998]; Hidalgo et al. 2004 [1997]). El cacicazgo de Codpa se estableció en 1648, escindiéndose del cacicazgo de Tacna, para cuyo gobierno fue designado Diego Cañipa (Hidalgo 2004 [1987]). Hacia finales del siglo XVIII el cacicazgo estaba compuesto por 18 pueblos, divididos en dos doctrinas. Por el sur, la doctrina de Codpa, integrada por los pueblos de Codpa, Esquiña, Pachica, Timar, Ticnamar, Saxamar, Umagata y Livilcar. Hacia el norte, la doctrina de Belén, constituida por Belén, Socoroma, Putre, Pachama, Putre, Parinacota, Choquelimpe, Guallatiri, Sora y Churiña (Figura 1). La población del Cacicazgo de Codpa, predominantemente indígena, había aumentado de 2.789 en 1750 (Hidalgo 1978) a 3.499 en 1773 (Hidalgo et al. 2004) en coherencia con el aumento demográfico de la región, para luego experimentar una nueva disminución a principios del siglo XIX (Hidalgo e Inostroza 2019). La provincia de Arica estaba exenta de la mita de Potosí, convirtiéndola en una zona propicia para la inmigración de sujetos forasteros que escapaban de las presiones que implicaba la mita, en una lógica que muestra continuidad con el antiguo tránsito vertical (Durston e Hidalgo 2004 [1999], de sujetos provenientes sobre todo de localidades Carangas y Pacajes (Inostroza 2019).

Durante las rebeliones andinas que se extendieron por gran parte del sur andino (O'Phelan 1988; Sala i Vila 1996; Thomson 2006; Serulnikov 2006; entre otros) el cacique de Codpa, Diego Felipe Cañipa, fue degollado por los "indios rebeldes" en 1781 (Hidalgo 1986, 2004 [1996]:260). Como era común, ya que lo había establecido la autoridad metropolitana, el cacicazgo quedó bajo el mando de su hijo, Eugenio Cañipa, en este nuevo escenario que hemos mencionado, marcado por la decadencia de la autoridad cacical (Hidalgo 1986; O'Phelan 1988). Coherente con esta situación, la presencia del cacique sucesor es escasa en la documentación de la época. Una de las ocasiones en que fue mencionado fue para quejarse de su accionar. En 1788, los alcaldes de los pueblos de Timar, Saxamar y Tignamar enviaron una carta al Gobernador Subdelegado informando de la situación miserable de sus parcialidades, alegando que el cacique Eugenio Cañipa no les había asignado tierras de repartimiento (Hidalgo et al. 1988:99-106). Posteriormente, en 1793, Eugenio Cañipa renunció a cobrar los tributos de esta doctrina porque en ella "no podía ejercer una autoridad efectiva" (Hidalgo y Durston 2004 [1998]:533). Así, la rebelión de 1781, como las reformas borbónicas anteriores y posteriores a ese movimiento, terminaron por deslegitimar a la figura del cacique, que desde antes era percibido como un agente del régimen colonial (Hidalgo y Durston 2004 [1998]; O'Phelan 1988; Thomson 2006; Serulnikov 2006). En adelante, el cobro del tributo en la doctrina de Belén parece haber quedado en manos de un funcionario español, Lucas San Martín, identificado como "enterador de tributos" en 1796 .

A partir del análisis de documentación de origen eclesiástico -en particular registros parroquiales- y su triangulación con otros registros administrativos (dos revistas y un padrón), se han podido reconstruir diversos aspectos de las poblaciones que habitaban los pueblos de indios de la doctrina de Belén (Inostroza 2019) ${ }^{4}$. Las inscripciones de sacramentos corresponden a registros de bautizos (1763 a 1834), casamientos (1774 a 1853) y defunciones (1773 a 1853), además de varios otros documentos elaborados por los curas doctrineros ${ }^{5}$. Esta información fue complementada con los datos contenidos en las Revistas del cacicazgo de Codpa de 1750 (Hidalgo 1978), la revisita a los Altos de Arica de 1772/73 (Hidalgo et al. 2004) y el Padrón de la Doctrina de Belén de 1813 (Hidalgo et al. 1988).

En un primer avance, al observar comparativamente las redes sociales de la doctrina de Belén del periodo que circunda la rebelión -por medio de la institución del compadrazgo- se verificó que tanto el cacique Diego Felipe Cañipa (residente en Codpa-Livilcar) como el segunda, Esteban Gutierres (habitante de Socoroma), tenían menos lazos sociales que los sujetos "principales" de Belén y Socoroma, lo que a nuestro juicio era evidencia del mayor peso social (probablemente político) y prestigio que habían alcanzado las autoridades del cabildo indígena (Inostroza 2011).

La documentación eclesiástica muestra una gran cantidad de personas participando en los gobiernos locales, tanto en el aspecto político (principalmente alcaldes) como en el religioso (la mayoría de ellos mayordomos), resolviendo problemas civiles, económicos y administrativos. Los datos reunidos en el conjunto de documentos evidencian los cargos locales ocupados por habitantes de los distintos pueblos en algunos de los años en que ejercieron como tales.

A continuación mostraremos la numerosa cantidad de autoridades locales que se suceden en diferentes cargos entre 1782 y 1813 en el conjunto de la doctrina. Posteriormente analizaremos los distintos aspectos sociales, religiosos y económicos que caracterizan sobre 


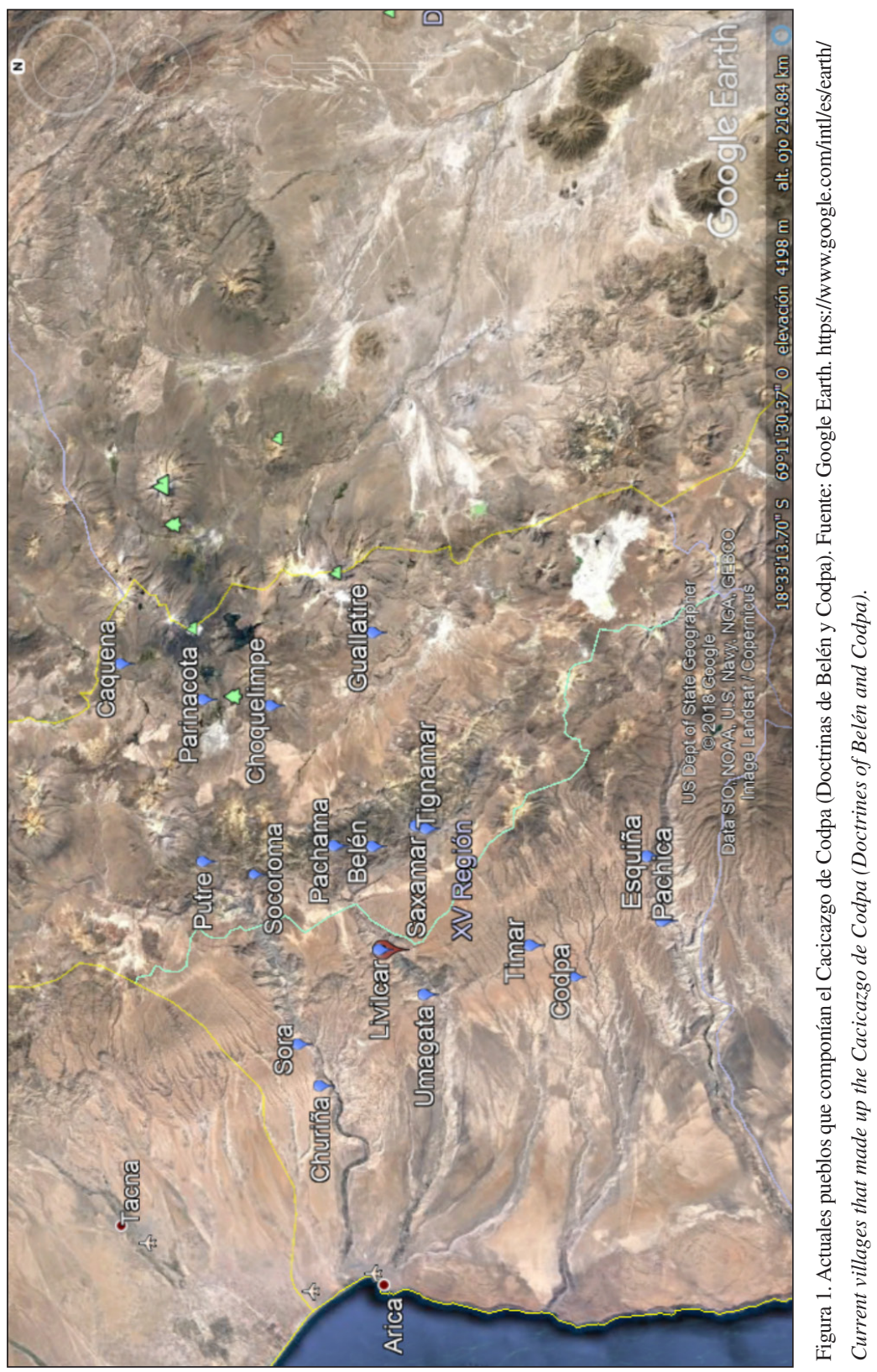


todo a las autoridades de Belén y Socoroma, intentando comprender las diversas dimensiones que caracterizaba al liderazgo étnico en esa zona. Lo que presentaremos a continuación es una información parcial, pues no se cuenta con un documento oficial que entregue la información exhaustiva.

Entre 1773 y 1833 se encontraron 173 menciones de autoridades civiles y religiosas de distintos pueblos de la doctrina, dentro de las que se menciona a tres caciques, cuatro autoridades españolas, 29 sujetos ejerciendo alguna función religiosa (cantor, fabriquero, mayordomo o sacristán), 15 principales y 95 alcaldes (mayores y ordinarios). El primer aspecto que nos interesa destacar es la proliferación de los cargos del cabildo con posterioridad a la rebelión de Tupac Amaru. Solo ocho autoridades fueron identificadas antes de 1781; cuatro de ellas mencionadas en la Revisita de 1772/73 y cuatro mencionadas en los libros de la Parroquia de Belén. En los registros parroquiales se repiten Asencio Maquera (principal del ayllu Mancasaya de Belén) y Esteban Gutierres (segunda, habitante de Socoroma). Se registran además algunos sujetos como principales, aunque su mención parece corresponder más a un grupo de notables. De hecho, las referencias incluyen a una mujer, Isabel Mamani, quien fue registrada junto a su marido, Benito Alanoca. Otros sujetos que fueron inscritos con esta categoría eran reconocidos en los registros como alcaldes pasados. En otras palabras, se reconoce claramente un grupo de mayor prestigio y estatus, quienes ocuparon preferentemente cargos civiles o religiosos. El investigador socoromeño, Carlos Choque (quien ha ejercido cargos en el pueblo de Socoroma) comenta que en la actualidad "Una vez que termina el sistema de cargos, el integrante de la comunidad es considerado 'pasado' o 'principal", (Choque 2015:33). Respecto de las funciones de estas autoridades, los alcaldes tenían jurisdicción sobre los pleitos, la distribución de las tierras y la normativas de moral doméstica, mientras que los caciques y principales (en otras palabras, las autoridades políticas) tenían la responsabilidad de recolectar el tributo o tasa que pagaba cada indio menor de 50 años, administrar los 'repartimientos', las levas de mano de obra para las obras específicas como la construcción de iglesias y caminos, y el cumplimiento de mitas o trabajos solicitados por el estado colonial (Hidalgo y Durston 2004 [1998]).

La primera autoridad que se tiene registro con posterioridad al levantamiento indígena, fue el español Isidro Quiroga, inscrito como gobernador en $1783^{6}$. A continuación, en 1785 , se comienzan a registrar nuevamente autoridades étnicas. De esta manera, en el segundo periodo de nueve años (17821790) se identificaron un total de 18 autoridades. Sin embargo, debemos destacar que el verdadero aumento de las autoridades del cabildo comenzó con mayor frecuencia a partir de 1790 . Hasta 1789 se registraron autoridades solo en Belén y Socoroma (pueblos que desde la creación de la doctrina de Belén se disputaron el puesto de "cabecera de doctrina"), pero en la década de 1790 se reconocen autoridades de los otros pueblos, probablemente ante nuevas disposiciones administrativas. En 1792, el Intendente Álvarez y Jiménez visitó la provincia indicando que en cada pueblo de la nueva doctrina de Belén -creada en 1777- debía haber un alcalde de naturales, mientras que en Belén, "cabecera de la doctrina", se establecían el alcalde mayor, el alcalde ordinario y dos alguaciles. Todos en su conjunto formaban el cabildo, que era presidido por el alcalde ordinario de españoles, residente en Arica o en sus valles costeros. Además, en esta ocasión Álvarez y Jiménez creó el cargo de procurador y mantuvo el de segunda "que pidieron los indios les fuese nombrado para el Pueblo de Belem" (Barriga 1948:117). A partir de su mención en los registros eclesiásticos podemos observar que el cargo de alcalde mayor recayó en sujetos de Belén, Socoroma y Putre, mientras que el cargo de "segunda" fue ocupado por personas de Socoroma y Belén. Es así que, en los nueve años que restan del siglo XVIII, se registraron a otras 40 autoridades, cifra bastante más significativa que los registrados en los nueve años previos. Posteriormente, entre 1800 y 1812 se reconocieron otras 42 autoridades. Lo importante es mostrar que esta alta frecuencia se mantuvo al menos hasta 1810, lo que evidencia que no fue un proceso transitorio, sino que, por el contrario, el fortalecimiento del cabildo en los pueblos indígenas inició una nueva etapa en la política de las comunidades de la doctrina de Belén 7 . Desde 1813 (en coherencia con el proceso forjado por la constitución de las cortes de Cádiz) se observan nuevas modificaciones en la denominación de los cargos, sin embargo, se repiten algunos sujetos del periodo anterior: Justo Agnocuti, Florentino Bustos y Eugenio Guanca de Belén; Bacilio Gutierres de Socoroma y Nicolás Madueño de Churiña. Finalmente, en el periodo que transcurre entre $1817 \mathrm{y}$ 1833, disminuye notoriamente la identificación de las autoridades, manteniéndose exclusivamente la figura del principal y del alcalde, situación que coincide con lo observado en Tinquipaya (Vicent 2015). Ahora bien, pese a que se observa una presencia constante de autoridades indígenas, la frecuencia de su registro podría estar reflejando tanto una mayor participación del cabildo en los asuntos públicos como el aumento de esos cargos (Figura 2).

Las altas frecuencias de 1773 y 1813 corresponden a registros censales que, por lo tanto, muestran el total de autoridades presentes en el conjunto de la doctrina. Exceptuando ambos registros, en mirada diacrónica, se observa un aumento de autoridades en los 


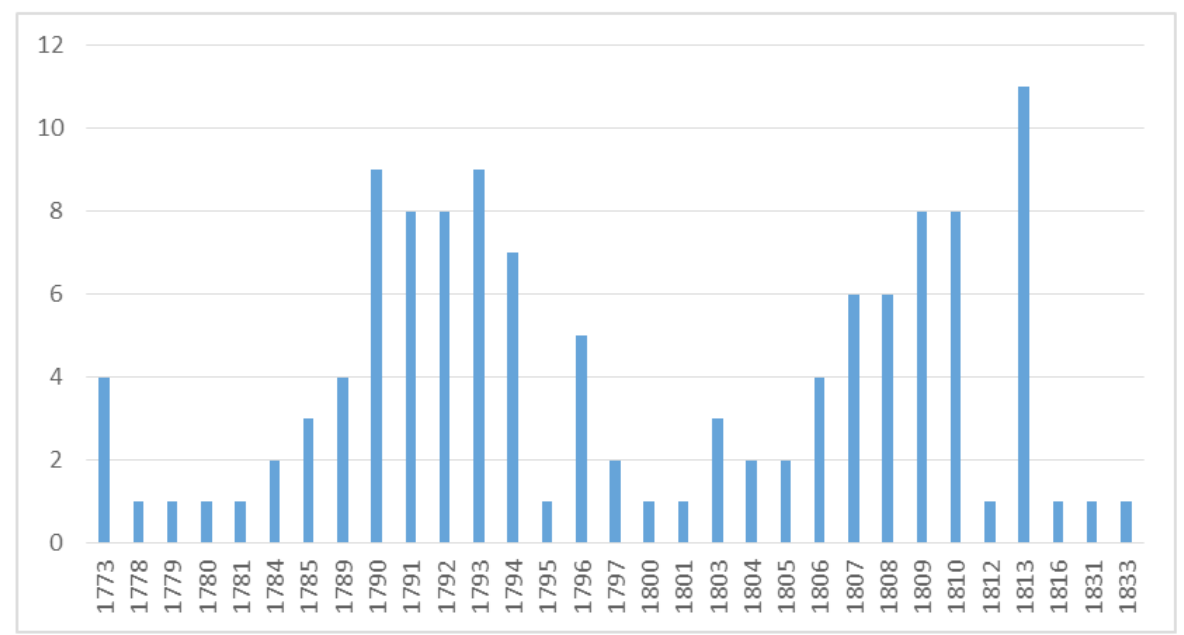

Figura 2. Frecuencia de autoridades. Doctrina de Belén, 1773-1833.

Frequency of authorities. Doctrine of Belén, 1773-1833.

registros correspondientes a los periodos 1790-1794 y más tarde entre 1806 y 1810 . El primero coincide con la visita y reformas al cabildo indígena que instituyó el intendente Álvarez y Jiménez. El segundo periodo podría corresponder al proceso de juntas de gobierno y abolición de los cacicazgos identificada por O'Phelan entre 1809 y 1814 (1988:15). La notoria disminución de autoridades en 1812 puede responder a las modificaciones en el sistema de gobierno que impulsaron las cortes de Cádiz. En ese aspecto, es interesante además destacar que en el registro de 1813 se identifica a Florentino Bustos como alcalde en Belén, quien ejerció cargos en 1809 y 1813 . Se trata de un hijo de "forastero agregado", residente en el pueblo. Esta situación, en coherencia con los procesos que hemos mencionado anteriormente, muestra cómo otros sujetos, en este caso de origen forastero, se integraron al gobierno comunal, lo que indica que la categoría de originario va perdiendo significancia e influencia en este periodo.

\section{Mayordomía: Dimensión Religiosa de la Autoridad}

El cargo civil, prestigio y posición social de los alcaldes y demás autoridades, estaba acompañado de deberes religiosos. Además de cumplir la función de padrinos, su rol en el mundo ritual de la comunidad se manifestaba a partir de la participación de varios de ellos como mayordomos de alguna de las dos cofradías que existían en Belén. De la cofradía "Nuestra Señora de la Concepción" fueron mayordomos: Bartolomé Gaspar y Sebastián Yanque (1778) ${ }^{9}$, Fernando Calle (1778-1780), Ramos Larva (1780-1782), Asencio Maquera (1782-1784), Hilario Ramos (1784),
Josef Larva (1785-1787), Jacinto Tarque (1787, 1789$1791)^{10}$, Antonio Nina (1790-1792), Juan Chrisóstomo Larva (1792), Tomás Marca (1801-1807), este último probablemente fue mayordomo hasta su muerte en $1810^{11}$. De la cofradía "Nuestro Señor o de Nuestro Amo", fueron mayordomos Andrés Vásquez (1778, $1780)^{12}$, Fernando Larva (1787) ${ }^{13}$, Juan Alanoca (1795), Antonio Larva (1797), Santiago Larva (1804), Isidro Marca $(1807)^{14}$ y Feliciano Larva (1809) ${ }^{15}$. Es así como se evidencia que al menos 15 de los 29 mayordomos realizaron esta función antes o después de detentar un cargo del cabildo, aunque preferentemente el cargo civil precedió al religioso (Tabla 1), lo que confirma que en las localidades de la doctrina de Belén ambas dimensiones estaban unidas, o al menos que eran los mismos sujetos los que cumplían las diferentes funciones de liderazgo que requería el pueblo.

Se mencionan además otros mayordomos al servicio de alguna de las tres iglesias de Belén. De la Iglesia Parroquial: Felipe Maquera y Santos Blas en 1784, Juan Nina y el español Isidro Quiroga en $1804^{16}$. De la Ermita de Nuestra Señora fueron mayordomos: Miguel Gaspar (1786), Isidro Quiroga (1787) y Fernando Larva (1788). Pedro Orellano fue nombrado mayordomo de la capilla de Santa Bárbara en 1778. Además, se menciona a Pablo Loaiza (español) como mayordomo de las ánimas, en $1779^{17}$. No hay evidencia de mayordomías anteriores asociadas a las iglesias, lo que hace probable que fuese el cura Mariano Pacheco el que haya propiciado estos cargos para el mejor cuidado de las alhajas y utensilios de los templos. Como queda manifestado, los escasos sujetos españoles que habitaron en el pueblo, aunque no ocuparon cargos del cabildo indígena sí realizaban funciones religiosas en las mayordomías del pueblo, 
Tabla 1. Autoridades religiosas y sus cargos civiles. Belén, 1773-1813.

Religious authorities and their civil positions. Belén, 1773-1813.

\begin{tabular}{|c|c|c|c|c|}
\hline Nombre & Cargo & Cofradía & Ayllu & Periodo \\
\hline \multirow{2}{*}{ Alanoca Juan } & Alcalde mayor & \multirow{2}{*}{ Nuestro Amo } & \multirow{2}{*}{ Mancasaya } & $1784,1794,1797$ \\
\hline & Mayordomo & & & 1795 \\
\hline \multirow{2}{*}{ Bustos Florencio } & Alcalde (O y M) & & & 1809-1810-1813 \\
\hline & Fabriquero & & & 1811 \\
\hline \multirow{2}{*}{ Calle Fernando } & Mayordomo & \multirow{2}{*}{ NS Concepción } & \multirow{2}{*}{ Aransaya } & $1778-1780$ \\
\hline & Segunda & & & 1793 \\
\hline \multirow{2}{*}{ Cutipa Narciso } & Segunda & \multirow{2}{*}{$?$} & & 1778 \\
\hline & Mayordomo & & & 1778 \\
\hline \multirow{2}{*}{ Gaspar Miguel } & Mayordomo & \multirow{2}{*}{ NS Concepción } & & 1786 \\
\hline & Alcalde Mayor & & & 1790 \\
\hline \multirow{2}{*}{ Larva Antonio } & Mayordomo & \multirow{2}{*}{ Nuestro Amo } & & 1797 \\
\hline & Alcalde & & & $?$ \\
\hline \multirow{2}{*}{ Larva Fernando } & Alcalde & \multirow{2}{*}{ NS Concepción } & \multirow{2}{*}{ Mancasaya } & 1785 \\
\hline & Mayordomo & & & $1787-1788$ \\
\hline \multirow{2}{*}{ Larva Jossef } & Alcalde mayor & \multirow{2}{*}{ NS Concepción } & \multirow{2}{*}{ Aransaya } & 1785,1793 \\
\hline & Mayordomo & & & $1785-1787$ \\
\hline \multirow{2}{*}{$\begin{array}{l}\text { Larva Juan } \\
\text { Chrisostomo }\end{array}$} & Alcalde mayor & \multirow{2}{*}{ NS Concepción } & \multirow{2}{*}{ Aransaya } & 1791 \\
\hline & Mayordomo & & & 1792 \\
\hline \multirow{2}{*}{ Maquera Asensio } & Alcalde mayor & \multirow{2}{*}{ NS Concepción } & \multirow{2}{*}{ Mancasaya } & 1780 \\
\hline & Mayordomo & & & $1782-1784$ \\
\hline \multirow{2}{*}{ Marca Isidro } & Mayordomo & \multirow{2}{*}{ Nuestro Amo } & & 1807 \\
\hline & Alcalde ordinario & & & 1809 \\
\hline \multirow{2}{*}{ Marca Tomas } & Alcalde ordinario & \multirow{2}{*}{ NS Concepción } & \multirow{2}{*}{ Mancasaya } & 1789 \\
\hline & Mayordomo & & & $1801-1807$ \\
\hline & Mayordomo & & & 1804 \\
\hline Nina Juan & Alcalde & lgi Parroquial & & 1813 \\
\hline & Gobernador & & & 1782 \\
\hline Quiroga Isidro & Mayordomo & $\begin{array}{l}\text { Ermita NS/Igl. } \\
\text { Parroquial }\end{array}$ & & $1787,1789,1804$ \\
\hline & Principal & & & 1773 \\
\hline Kamos nario & Mayordomo & Ns Concepcion & Aransaya & 1784 \\
\hline & Mayordomo & & & $1787,1789-1791$ \\
\hline Tarque Jactito & Alcalde interino & Ns Concepcion & Aransaya & 1808 \\
\hline
\end{tabular}

NS: Nuestra Señora / O: Ordinario / M: Mayor

mostrando su integración en la comunidad. Como mayordomos, debían encargarse del cultivo de las tierras de la cofradía para obtener recursos que permitieran financiar los gastos religiosos, además de cuidar las pertenencias y aseo de la iglesia. A su vez, los alcaldes y el segunda, cumplían un rol fiscalizador, ya que los mayordomos debían dar cuenta ante ellos, todos los años, del producto de las chacras de la cofradía y de las 
limosnas ${ }^{18}$. El cargo de fabriquero parece ser posterior. La primera referencia que poseemos corresponde a Bacilio Gutierres, de Socoroma, fabriquero en $1797^{19}$. En Belén se identificó a Florencio Bustos en este cargo en $1811^{20}$, y más tarde a Mariano Gutierres, también de Socoroma en $1827^{21}$. En cuanto a su participación en los sacramentos cristianos, se abordaron anteriormente los antecedentes jurídicos que otorgaban a las autoridades una función específica, particularmente en el ritual del matrimonio: participar como testigos (Inostroza 2013b). Pero, aunque esta participación era propia de sus cargos, refleja la importancia social de su voz y su presencia al momento de avalar situaciones sociales relevantes para la comunidad, como fue la conformación de las nuevas familias.

El Segundo Concilio Limense (1567-1568) estipulaba la elección de dos mayordomos que debían ser nombrados "juntamente con el cura" (Vargas Ugarte 1951:251). En Belén, esta elección se realizaba entre los cófrades: "En el pueblo de Santiago de Tocoroma [Belén], en la iglesia parroquial del dicho pueblo en trece de diciembre de mil y seiscientos y setenta y seis años fue nombrado por votos de los cofrades de nuestra señora de la Limpia Concepción Pedro Larua por mayordomo de la dicha cofradía" 22 . Es probable que, con el tiempo, y ante la probable ausencia de "miembros" de la cofradía ${ }^{23}$, la elección recayera en las otras autoridades. Posiblemente ocurría de manera similar al cargo de alférez, quienes preferentemente eran voluntarios, pero de no haberlos, eran designados por el cura o la comunidad, y su nombramiento era tomado como una obligación (Barriga 1948:103, 116).

En cuanto a la organización dual, se han documentado otros casos durante el siglo XVIII cuyas cofradías se organizaban a partir de la alternancia de ambos ayllus. De todas maneras, la documentación que permite observar cómo se organizaban las cofradías en función de la estructura social de las comunidades es muy escasa ${ }^{24}$. En el caso de Belén, de igual manera que los cargos civiles, los mayordomos procedían indistintamente de alguno de los dos ayllus (Tabla 1). Por otra parte, en un caso probablemente excepcional, el cura manifestó su aprobación para un séptimo periodo de Tomás Marca como mayordomo de Nuestra Señora del Milagro ${ }^{25}$. Además, se registraron otros cargos religiosos en Belén; Agustín y Tomás Cruz fueron registrados como sacristanes en 1778, y Tomás Vega en $1789^{26}$. Santiago Cutipa fue identificado en la misma función en 1778, $1789^{27}$ y $1791^{28}$ lo que hace probable que la cumpliera de manera permanente. Posteriormente, Luis Cutipa fue mencionado en el mismo cargo en 1813 (Hidalgo et al. 1988). Además, se mencionaron dos cantores, Clemente Vega (español) en $1789^{29}$ y Gregorio Calle en $1801^{30}$.

Las características y funciones de las autoridades (que integraban aspectos civiles y religiosos) que se observan en los pueblos de los Altos de Arica en este periodo, muestra de forma detallada cómo funcionó el proceso evangelizador descrito por van Kessel, quien asegura que en el siglo XVIII:

...el régimen eclesiástico se demostró más eficaz en la zona imponiéndole sus reglas administrativas con firmeza y logrando un funcionamiento muy razonable del aparato litúrgico-parroquial con la asistencia de cantores, fabriqueros y demás funcionarios laicos de menor rango (van Kessel 1989:10) ${ }^{31}$.

\section{Autoridades, Compadrazgo y Redes Sociales}

Analizar las relaciones de compadrazgo $0^{32}$ nos permite observar otras dimensiones del prestigio de las autoridades étnicas, para lo cual nos hemos enfocado en las autoridades de Belén y Socoroma, principales pueblos de la Doctrina de Belén. En la Tabla 2 ordenamos los datos de manera decreciente, a partir de lo cual se percibe claramente que el mayor prestigio alcanzado por los sujetos de autoridad en base al padrinazgo tiene relación con la mayor extensión geográfica de sus redes sociales. Se puede observar, además, que aquellos individuos con un tejido social más amplio integran en él a otros sujetos de autoridad (en la Tabla 2: c/a).

En la Tabla 3 se observa a las autoridades de Belén según el número de relaciones de padrinazgo que establecieron durante sus vidas $(\mathrm{P})$, registrados en los libros parroquiales. Como mencionamos anteriormente, los sujetos que constituyeron redes sociales más extensas, presentan lazos tanto dentro como fuera de su pueblo de origen, incluyendo tres o cuatro localidades. El pueblo que se repite en mayores ocasiones es Pachama (Pach), seguido de Guallatiri (G). Luego se incluyen en una ocasión Choquelimpe (Choq) y las localidades foráneas de Sacsamar (Codpa), Turco y Carangas ${ }^{33}$.

En la Tabla 2 incluimos el ayllu de origen de cada sujeto para demostrar que los distintos cargos fueron ocupados por integrantes de ambas parcialidades (Inostroza 2016, 2019).

Se observan dos situaciones análogas entre quienes encabezan el listado (Tabla 3). En primer lugar, Juan Alanoca presentó una red más diversa geográficamente, que incluye cuatro localidades de la doctrina y a un sujeto forastero, tributario de Carangas. Por otra parte, Francisco Ocharan integró entre las relaciones de compadrazgo a una mayor cantidad de autoridades, lo que, desde el punto de vista de la asimetría (Mintz y Wolf 1950), dotaría a Ocharan de mayor prestigio sobre las demás autoridades ${ }^{34}$.

En Socoroma ocurrió algo similar (Tabla 4). Bacilio Gutierres, el sujeto con mayor número de padrinazgos, extendió sus redes sociales a mayor cantidad de localidades, 
Tabla 2. Autoridades indígenas y relaciones de padrinazgo.

Indigenous authorities and godfathering relationship.

\begin{tabular}{|c|c|c|c|c|}
\hline Año & Nombre & Cargo & $\mathrm{c} / \mathrm{a}$ & Orig. compadres \\
\hline 1794 & Gutierres Bacilio & A. Mayor (Soc) & 4 & $\begin{array}{l}\text { Soc-Put-Par-Caq- } \\
\text { Sora-Chu-Calac }\end{array}$ \\
\hline 1789 & Tapia Fernando & A. Mayor (Soc) & 1 & $\begin{array}{l}\text { Soc-Chu- } \\
\text { Sora-Choq }\end{array}$ \\
\hline 1784-94-1797 & Alanoca Juan & A. Mayor (B) & 1 & $\begin{array}{l}\text { B-Put- Sora- } \\
\text { Choq-Carangas }\end{array}$ \\
\hline 1789 & Ocharan Francisco & A. Mayor (B) & 2 & B-G \\
\hline $1779-1796$ & Flores Francisco & A. Mayor (Soc) & & Soc-Sora-Calac \\
\hline$<1773$ & Ramos Hilario & P. Aransaya (B) & 1 & B-Pach-G \\
\hline 1791 & Arias Francisco & A. Ord (Soc) & 1 & Soc-B-Put-Caq \\
\hline 1791 & Blanco Cruz & A Mayor (Soc) & 2 & Soc \\
\hline $1785-1793$ & Larva Joseff & A. Mayor (B) & 1 & B-Pach \\
\hline 1793 & Calle Fernando & Segunda (B) & 1 & B-Sacsamar \\
\hline$<1773$ & Gutierres Esteban & Segunda (Soc) & & Soc-Put \\
\hline 1790 & Gaspar Miguel & A. Mayor (B) & & $\mathrm{B}$ \\
\hline 1792 & Cruz Alejandro & A. Mayor (B) & & B-G-Pach \\
\hline 1792 & Chuquiguanca Carlos & A. Ord (Soc) & & Soc-Par \\
\hline$<1773$ & Maquera Asencio & P. Mancasaya (B) & & B-Pach \\
\hline 1785 & Mamani Julian & A. Mayor (Soc) & & Soc-Caqu \\
\hline 1792 & Flores Bernardo & A. Mayor (Soc) & & Soc \\
\hline 1792 & Flores Bernardo & A. Mayor (Soc) & & Soc-B \\
\hline 1793 & Maquera Martin & A. Ord (B) & & $B-G$ \\
\hline 1794 & Vasques Gregorio & A. Ord (B) & & B-Turco \\
\hline 1796 & Guanca Antonio & A. Ord (B) & & B-Pach \\
\hline 1790 & Agnocuti Josef & Alcalde (B) & & $\mathrm{B}$ \\
\hline 1785 & Larva Fernando & Alcalde (B) & & B \\
\hline 1796 & Condori Prudencio & Segunda (Soc) & & Chur \\
\hline 1789 & Mamani Tomás & A Ord (Soc) & & $\mathrm{X}$ \\
\hline
\end{tabular}

Soc: Socoroma/ Pu: Putre/ Par: Parinacota/ Caq.: Caquena/ Chu: Churiña/ B: Belén/ G: Guallatiri/ Choq: Choquelimpe/ Pach: Pachama/ Calac: Calacoto/ c/a: padrinazgo con otro sujeto de autoridad.

Tabla 3. Autoridades en Belén. 1773-1796.

Authorities in Belén. 1773-1796.

\begin{tabular}{|c|c|c|c|c|c|c|}
\hline Año & Nombre & Cargo & Ayllu & $\mathrm{P}$ & Autoridad & Orig. compadres \\
\hline 1784-94-97 & Alanoca J. & Alde. Mayor & M & 8 & Guanca A. & $\begin{array}{l}\text { B-Put-Sora- } \\
\text { Choq-Carangas }\end{array}$ \\
\hline 1789 & Ocharan F. & Alde. Mayor & M & 8 & $\begin{array}{l}\text { Maquera A. } \\
\text { Cruz A. }\end{array}$ & B-Guall \\
\hline 1773 & Ramos H. & Principal & A & 7 & Vasques G. & B-Pach-Guall \\
\hline $1785-793$ & Larva J. & Alde. Mayor & A & 5 & Aruviri V. & B-Pach \\
\hline 1793 & Calle F. & Segunda & A & 5 & Maquera A. & B-Sacsamar \\
\hline 1790 & Gaspar M. & Alde. Mayor & M & 4 & & B \\
\hline 1792 & Cruz A. & Alde. Mayor & A & 4 & & B-Guall-Pach \\
\hline 1773 & Maquera A. & Principal & M & 3 & & B-Pach \\
\hline 1793 & Maquera M. & Alde. Ord. & M & 2 & & B-Guall \\
\hline 1794 & Vasques G. & Alde. Ord. & A & 2 & & B-Turco \\
\hline 1796 & Guanca A. & Alde. Ord. & M & 2 & & B-Pach \\
\hline 1790 & Agnocuti J. & Alcalde & $\mathrm{A}$ & 2 & & B \\
\hline 1785 & Larva F. & Alcalde & M & 1 & & $\mathrm{~B}$ \\
\hline 1784 & Cutipa J. & Alcalde & A & 0 & & \\
\hline
\end{tabular}

M: Mancasaya/ A:Aransaya/ P: Padrinazgo. 
apadrinando a niños de todos los pueblos del valle (Socoroma, Putre, Parinacota, Caquena, Sora y Churiña) y a un hijo de forasteros de Calacoto (Obispado de La Paz). Además, apadrinó a hijos de otras cuatro autoridades de su pueblo. Ambos aspectos, extensión geográfica y lazos con varias autoridades, son elementos que otorgan mayor grado de prestigio a sujetos como Bacilio Gutierres, Juan Alanoca y Francisco Ocharan, demostrando que la extensión de la autoridad y el prestigio solo en algunos casos se extendía a nivel de doctrina. color gris (arriba a la izquierda del gráfico) el cacique, residente en el pueblo de Codpa. En celeste, se observa a españoles o mestizos que se integran en las redes de las autoridades. Este aspecto en particular nos permitió observar la diversidad y cualidad de la composición de las redes de sociabilidad de los alcaldes en las que se integran sujetos del común, otras autoridades, forasteros, españoles y mestizos.

Este análisis, devela varias situaciones. En primer lugar, que no hay diferencia en el tamaño de la red de

Tabla 4. Autoridades en Socoroma. 1773-1796.

Authorities in Socoroma. 1773-1796.

\begin{tabular}{llllll}
\hline \multicolumn{1}{c}{ Año } & \multicolumn{1}{c}{ Nombre } & \multicolumn{1}{c}{ Cargo } & P & \multicolumn{1}{c}{ Autoridad } & Orig compadres \\
\hline 1794 & Gutierres B. & Alde. Mayor & 19 & $\begin{array}{l}\text { Mamani S. } \\
\text { Vasques B. } \\
\text { Madueño N. } \\
\text { Mita F. }\end{array}$ & $\begin{array}{l}\text { Soc-Pu-Par- } \\
\text { Caq-Sor-Chu- } \\
\text { Calac }\end{array}$ \\
\hline 1789 & Tapia F. & Alde. Mayor & 11 & Arias F. & $\begin{array}{l}\text { Soc-Chur- } \\
\text { Sor-Choq }\end{array}$ \\
\hline $1779-1796$ & Flores F. & Alde. Mayor & 8 & & Soc-Sor-Calac \\
\hline 1791 & Arias F. & Alde. Ord & 7 & Quiroga I. & Soc-B-Pu-Caq \\
\hline 1791 & Blanco C. & Alde. Mayor & 7 & $\begin{array}{l}\text { Guanca P. } \\
\text { Arias F. }\end{array}$ & Soc \\
\hline$<1773$ & Gutierres E. & Segunda & 5 & & Soc-Pu \\
\hline 1792 & Chuquiguanca C. & Alde. Ord & 4 & & Soc-Par \\
\hline 1785 & Mamani J. & Alde. Mayor & 3 & & Soc-Caq \\
\hline 1792 & Flores B. & Alde. Mayor & 3 & & Soc \\
\hline 1796 & Condori P. & Segunda & 1 & & Chu \\
\hline 1789 & Mamani T. & Alde. Ord & 0 & & \\
\hline P: Padrinazgo. & & & & &
\end{tabular}

\section{Redes Sociales de Autoridades del Cabildo en Belén}

A partir del programa UCINET (Borgatti et al. 2002) se graficó la red social de los sujetos que participaron en el cabildo indígena en el pueblo de Belén en el periodo correspondiente al siglo XVIII (Figura 3). Los cuadrados en color negro corresponden a autoridades del ayllu Mancasaya y los cuadrados rojos a autoridades de Aransaya. Además contiene los lazos establecidos por sus esposas (cuadrados verdes), pues ellas participaron en numerosas ocasiones como madrinas en los registros.

La red incluye todos los lazos establecidos a partir del compadrazgo con otros sujetos: apadrinamiento, compadrazgo por un hijo propio y compadrazgo por matrimonio ${ }^{35}$. Los colores de los sujetos representan su origen: Los azules, que son mayoría, corresponden a sujetos indígenas, habitantes del mismo pueblo que el compadre. En amarillo, otros indígenas, habitantes de otro pueblo de la doctrina. En morado, los sujetos identificados como forasteros. Casi imperceptible en los sujetos que ocuparon el cargo de alcalde mayor con quienes fueron alcaldes ordinarios. Por ejemplo, entre Tomás Marca alcalde ordinario (Inostroza 2013b) y Francisco Ocharan alcalde mayor (Inostroza 2013a). Ahora bien, el análisis de redes muestra al alcalde ordinario mejor posicionado que el alcalde mayor, lo que se debe a que estos lazos dependen en gran medida del número de esposas y el número de hijos (Inostroza 2019) y Tomás Marca fue la autoridad que contrajo una mayor cantidad de matrimonios. Por lo tanto, evidencia una situación cotidiana patente en gran parte de los estudios etnográficos: una mayor cantidad de esposas a lo largo de su vida y/o un mayor número de hijos fueron situaciones familiares que contribuyeron a incrementar la red social de estos sujetos, contar con una mayor red de ayuda o ayni, y por tanto a extender su prestigio ${ }^{36}$.

Pero, además, el diagrama de la red pone en evidencia otra situación de la que hemos dado cuenta al inicio de este trabajo: la relativa homogeneidad entre los sujetos de autoridad. En ese sentido, uno de los indicadores de redes que entrega este recurso computacional es la densidad. 


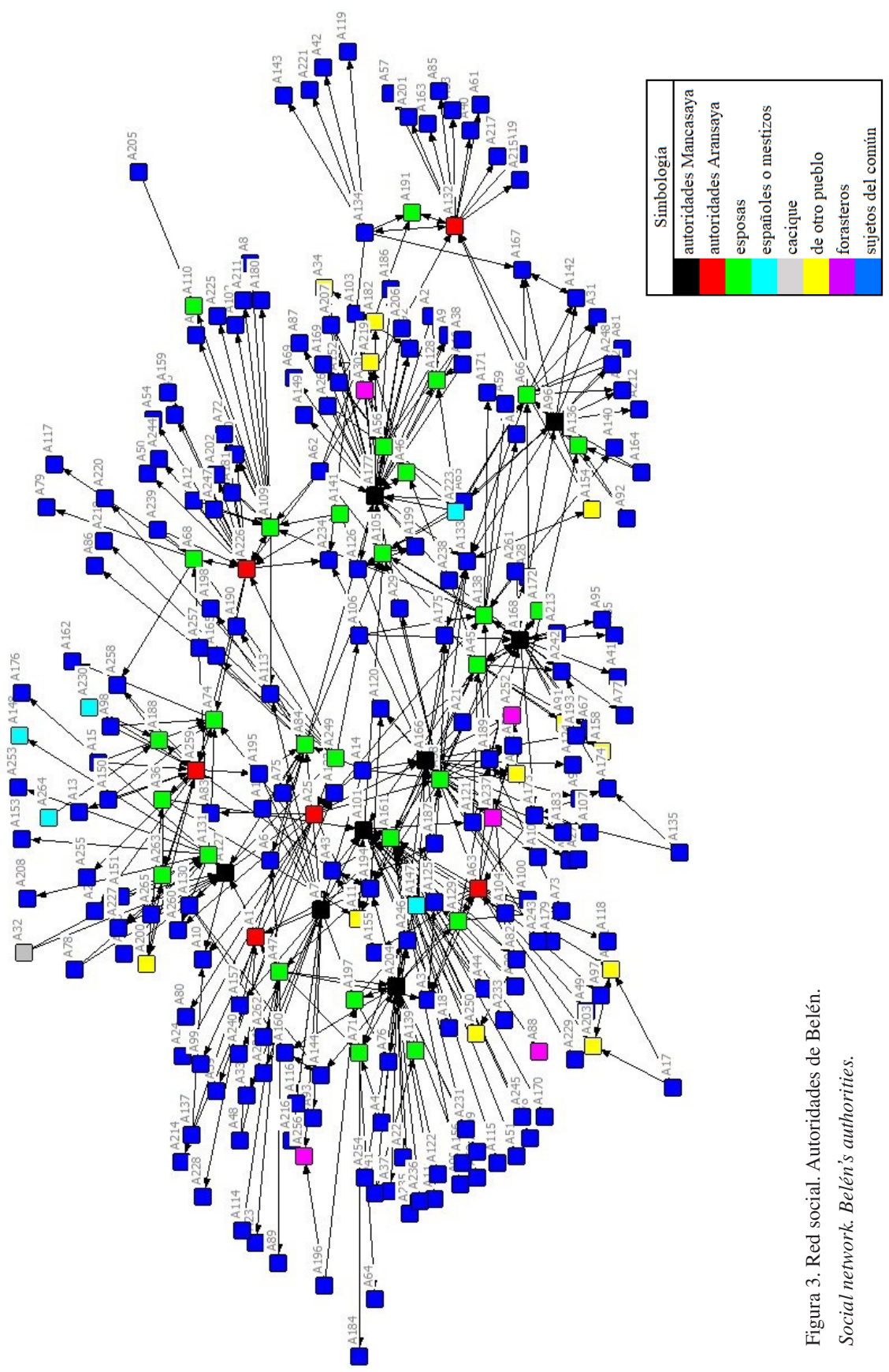


En este caso, por ejemplo, la red, compuesta por 265 personas que tienen al menos un nexo con otro integrante, presenta una densidad muy baja $(0,4 \%)$, lo que se traduce en que no hay importantes nodos que concentren la mayoría de las relaciones. Ahora bien, esto no quiere decir que no existan diferencias de prestigio entre los sujetos de autoridad indígena (Inostroza 2016, 2019), pero pensamos que estas divergencias, tanto en el grado de autoridad como de riqueza, no eran significativas, al punto de causar serias diferencias sociales al interior de la comunidad.

\section{Dimensión Económica del Prestigio}

En la doctrina de Belén los tributarios debían pagar a la Corona 6 pesos y 2 reales, cifra establecida en 1750 (Hidalgo 1987:213). En la Revisita de 1772/73, que registró a los sujetos de todo el Cacicazgo de Codpa (Doctrina de Belén y Doctrina de Codpa), se identificaron 779 tributarios, de los que se "rebajan" 20 hombres "necesarios para la recaudación de los reales tributos y servicios de la Iglesia..." (Hidalgo et al. 2004:192). Lamentablemente en la Revisita no se indica quiénes son los sujetos rebajados. Ahora, el Cacicazgo en 1773 estaba compuesto por 17 pueblos. Lo más probable, atendiendo a los intereses fiscales, es que se autorizara un cobrador por pueblo (cacique y/o segunda) $\mathrm{y}$, en consecuencia, los tres restantes -para completar los 20 exentos- fueran principales (en Belén y Codpa) o servidores de las iglesias (en el caso de Socoroma).

En otra oportunidad, habíamos propuesto que la autoridad, prestigio, influencia y papel jugado como alcaldes y mayordomos en varios casos, estuvieron acompañados de mayores recursos económicos (Inostroza 2016). Según el valor que pagaban los tributarios de Belén por diezmo de las crías de sus animales de origen europeo, se pudo estimar las diferencias en cuanto a recursos económicos. En promedio, cada tributario del pueblo debía pagar un diezmo de 4 reales (Inostroza 2016). Por otra parte, el pago promedio que debían realizar las 12 autoridades que aparecen en la lista en el pueblo de Belén asciende a 7 reales, cifra más elevada que el promedio de todo el pueblo. En la tabla 5 se observa el valor que debían pagar las autoridades y personajes principales, presentes en la lista de diezmos de 1787. Como punto de comparación, incluimos en la tabla a los dos españoles que pagaban diezmo: Isidro Quiroga y Clemente Vega.

Los datos reflejan la notoria diferencia en recursos de Isidro Quiroga (español, gobernador en 1783), quien superó en riqueza ampliamente a todas las autoridades, ya que pagaba 94 reales por los animales que poseía. No ocurre lo mismo con Clemente Vega ni con los otros dos mestizos inscritos en el documento de 1787, que no registran animales de origen europeo, pues la lista de diezmos no incluía camélidos andinos, que no pagaban el tributo eclesiástico. Suponiendo que el pago del diezmo reflejaba las diferencias en ingresos, se podría proponer que los sujetos de autoridad tenían más recursos que el promedio del pueblo, en base a los diezmos ( 4,8 reales). Los sujetos indígenas del pueblo de Belén con mayores recursos hacia 1787 eran Francisco Ocharan y Juan Alanoca, mientras que se puede afirmar que ellos, además de Antonio Guanca, Josef Agnocuti, Gregorio Vásquez y Tomás Marca, superaban el promedio de recursos de los habitantes del pueblo. La importancia económica de estos sujetos nos parecía indudable, lo que era reforzado por lo que evidenciaba el testamento de Francisco Ocharán secretario del cabildo indígena (Inostroza 2013a).

Sin embargo, el análisis de la lista completa de la doctrina nos advierte de otra situación que puede matizar

Tabla 5. Riqueza de autoridades y sujetos principales por animales según lista de pagadores de diezmo. Belén, 1787.

Wealth of authorities and main individuals based on heads of livestock they own, according to the tithe payers list. Belén, 1787.

\begin{tabular}{|c|c|c|c|c|c|c|c|c|c|c|}
\hline Nombre & Cargo & Vacas & $4 \mathrm{r}$ & Ovejas & $1 \mathrm{r}$ & Yeguas & $1 \mathrm{r}$ & Burras & $2 \mathrm{r}$ & Total $r$ \\
\hline Quiroga I. & Gob. & 10 & 40 & 50 & 50 & 4 & 4 & & & 94 \\
\hline Vega $C$. & Not. & & & 2 & 2 & & & & & 2 \\
\hline Ocharan F. & A. M. & & & 15 & 15 & 1 & 1 & 1 & 2 & 18 \\
\hline Alanoca J. & A. M. & & & 15 & 15 & 1 & 1 & 1 & 2 & 18 \\
\hline Guanca A. & A. $\mathrm{O}$. & & & 6 & 6 & 1 & 1 & 3 & 6 & 13 \\
\hline Agnocuti J. & A. O. & & & 4 & 4 & 1 & 1 & 2 & 4 & 9 \\
\hline Vasquez G. & A. O. & & & 6 & 6 & 1 & 1 & 1 & 2 & 9 \\
\hline Marca T. & A. O. & & & & & 1 & 1 & 2 & 4 & 5 \\
\hline Cruz A. & A. $\mathrm{O}$. & & & & & & & 2 & 4 & 4 \\
\hline Gaspar M. & A. M. & & & & & & & 2 & 4 & 4 \\
\hline Ramos I. & Ppal. & & & & & 1 & 1 & 1 & 2 & 3 \\
\hline Calle F. & Sda. & & & & & & & 1 & 2 & 2 \\
\hline
\end{tabular}

r: reales / A: Alcalde / M: Mayor. / O: Ordinario. / Gob: Gobernador. / Not: Notario. 
la conclusión anterior respecto de la relación: autoridades indígenas/recursos económicos. La lista de los feligreses de la doctrina que pagaban el tributo eclesiástico incluye a un total de 335 sujetos. El valor de sus animales suma 3.747 reales, lo que implica un promedio de 11 reales por persona. Ahora, como se puede observar en la Figura 4, la dispersión no es muy alta, lo que evidencia una homogeneidad en la riqueza de la población, salvo unos pocos sujetos que escapan de la generalidad.

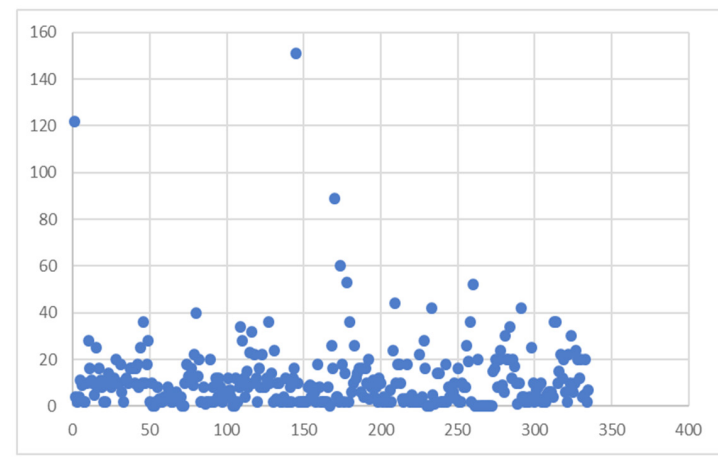

Figura 4. Dispersión de diezmos que pagaban (por crías de animales europeos) los feligreses de la Doctrina de Belén.

Dispersion of tithes paid by parishioners of the Belén Doctrine (for European animal offspring).
Pese a la mayoritaria uniformidad, 113 personas de las 335 de la lista (un tercio de la población) superaron el promedio de 11 reales por persona. De ellas, solo 15 sujetos han sido identificados como autoridades (tanto civiles como religiosas), lo que sugiere que los sujetos que ocuparon cargos de autoridad indígena no eran necesariamente los que tenían mayores recursos a nivel de doctrina (Tabla 6). Esta situación difiere de lo que habíamos observado anteriormente en el pueblo de Belén, donde se observaba cierta superioridad económica de los sujetos de autoridad sobre el común del pueblo (Inostroza 2016).

Escapa notoriamente en la dispersión Fernando Tapia de Socoroma, quien supera en recursos incluso a Isidro Quiroga, español que habitaba Belén (Inostroza 2011, 2019). Le siguen en orden decreciente: Pascual Condori (Putre), Basilio Ticona (Putre), Don Lorenzo Palsa (Haciendas, español), Domingo Medina (Putre), Salvador Tapia (Sora), Mateo Mayta (Choquelimpe) y Luis Nuñes (Pachama).

Estos antecedentes nos permiten sostener lo siguiente: tal parece que los sujetos que evidencian mayor riqueza son sujetos que habitan preferentemente Putre y las haciendas del valle bajo, en posesión principalmente de españoles (Marsilli e Hidalgo 1992),

Tabla 6. Autoridades de la doctrina que superan el promedio de reales que pagan los feligreses por diezmo.

Authorities of the Doctrine who exceed the average tithe paid in reales by parishioners.

\begin{tabular}{|c|c|c|c|c|c|}
\hline Nombre & Apellido & Pueblo & Total & Cargo & Año \\
\hline Fernando & Tapia & Socoroma & 151 & $\begin{array}{l}\text { Mayordomo } \\
\text { Alcalde mayor }\end{array}$ & $\begin{array}{l}1787 \\
1789\end{array}$ \\
\hline Isidro Don & Quiroga & Belén & 122 & $\begin{array}{l}\text { Gobernador } \\
\text { Mayordomo } \\
\text { Mayordomo } \\
\text { Mayordomo }\end{array}$ & $\begin{array}{l}1783 \\
1787 \\
1789 \\
1804\end{array}$ \\
\hline Pascual & Condori & Putre & 60 & $\begin{array}{l}\text { Fiscal } \\
\text { Alcalde mayor }\end{array}$ & $\begin{array}{l}1790 \\
1792\end{array}$ \\
\hline Basilio & Ticona & Putre & 53 & Alcalde mayor & 1790 \\
\hline Tomas & Mamani & Socoroma & 36 & Alcalde ordinario & 1789 \\
\hline Julian & Medina & Putre & 36 & Alcalde mayor & 1793 \\
\hline Fran[cis]co & Flores & Socoroma & 28 & $\begin{array}{l}\text { Alcalde mayor } \\
\text { Fiscal } \\
\text { Alcalde mayor }\end{array}$ & $\begin{array}{l}1779 \\
1791 \\
1796\end{array}$ \\
\hline Fran[cis]co & Guanca & Putre & 26 & Principal & 1796 \\
\hline Ildefonso & Zarsori & Putre & 26 & $\begin{array}{l}\text { Alcalde mayor } \\
\text { Principal }\end{array}$ & $\begin{array}{l}1791 \\
1791\end{array}$ \\
\hline Agustin & Condori & Putre & 20 & Alcalde mayor & 1790 \\
\hline Prudencio & Condori & Socoroma & 16 & $\begin{array}{l}\text { Segunda } \\
\text { Segunda } \\
\text { Segunda }\end{array}$ & $\begin{array}{l}1796 \\
1805 \\
1807\end{array}$ \\
\hline Torivio & Chino & Putre & 16 & Alcalde ordinario & 1790 \\
\hline Bernardo & Flores & Socoroma & 12 & $\begin{array}{l}\text { Alcalde mayor } \\
\text { Alcalde mayor }\end{array}$ & $\begin{array}{l}1792 \\
1810\end{array}$ \\
\hline Carlos & Chuquiguanca & Socoroma & 12 & $\begin{array}{l}\text { Alcalde } \\
\text { Alcalde ordinario }\end{array}$ & $\begin{array}{l}1810 \\
1792 \\
\end{array}$ \\
\hline Tomas & Manlla & Socoroma & 12 & Alguacil & 1793 \\
\hline
\end{tabular}


así como la localidad minera de Choquelimpe. Es muy probable que realizaran actividades vinculadas al comercio entre Arica y el Alto Perú (Hidalgo 1987). En ese sentido, el caso de Fernando Tapia en Socoroma es relevante, pues pese a su origen forastero ocupó el cargo de alcalde mayor en 1789, reflejando la paulatina inclusión de sujetos forasteros en el sistema de cargos, debido, tanto a su importancia económica como a los cambios político-administrativos posteriores a la rebelión de Tupac Amaru.

Es así como la situación analizada en la doctrina de Belén demuestra que, pese a que los sujetos de autoridad tuvieron una cuota mayor de recursos, sus ingresos se ven superados por otros agentes que habitaron la doctrina. Se podría proponer, en la línea de Wolf (1980) y Mayer (1974), que las relaciones de reciprocidad que les otorgaron el prestigio que sustentó sus liderazgos, así como su participación en las festividades locales, funcionaron como mecanismos de regulación de las diferencias económicas con los habitantes de sus pueblos.

\section{Propuestas Finales}

Hemos iniciado nuestro análisis con una revisión bibliográfica de los principales aportes del área andina sobre las autoridades locales: caciques o curacas, alcaldes mayores y cabildo indígena. Nuestra metodología ha ido de lo general a lo particular, pues pensamos que es importante poner en contexto los diversos aspectos sufridos por las autoridades étnicas relacionados con la figura del cacique, del cabildo y los alcaldes. Se mencionan algunos aspectos que se han documentado en otras localidades de la América colonial, que exceden del área andina, con el objetivo de ir identificando justamente aquellos elementos que pueden responder más al resultado de políticas coloniales que a manifestaciones locales, pues para nosotros como historiadores es importante ir destacando similitudes o diferencias con otros procesos, que permitan una mejor comprensión de ellos.

En el periodo Colonial las autoridades del cabildo indígena de la doctrina de Belén están ausentes en la documentación administrativa colonial, pero quedaron registrados en documentación que tiene un origen eclesiástico, ya que parte importante de sus funciones se cumplía en aspectos religiosos. A partir de su identificación en cargos de alcaldes y mayordomos, y de la reconstitución de las familias que componían el pueblo (Inostroza 2019), se ha podido comprobar que, en cuanto a la población indígena, corresponden a sujetos que provenían de familias originarias. Las familias de los sujetos consignados "originarios" tienen presencia en la Revisita de 1772/73 (Hidalgo et. al. 2004) y, en muchas ocasiones, ellos o sus padres estaban inscritos en el registro de 1750 (Hidalgo 1978). Solo al finalizar el periodo se observa la inclusión de sujetos de origen forastero entre la jerarquía político-social del pueblo (p.ej., el caso de Florentino Bustos, alcalde y fabriquero), posiblemente ligados a actividades económicas. Por otra parte, sus funciones políticas muchas veces se alternaban con cargos religiosos, tales como los de mayordomo, sacristán o fabriquero, y se complementaban con sus roles de padrinos y testigos en bautizos y matrimonios. En ese sentido, la incorporación de sujetos españoles, mestizos y forasteros a los cargos de las cofradías y al compadrazgo, así como en otros roles sociales como los de testigos y albaceas, son reflejo de un proceso que se había originado con anterioridad, la incorporación efectiva de estos sujetos a la comunidad.

Las características de la estructura del sistema de cargos que se observa en la doctrina de Belén coinciden en algunos aspectos y se diferencia en otros con procesos similares que se han documentado en los Andes y en la América colonial. La frecuencia de autoridades del cabildo indígena que hemos desplegado demuestra que las políticas implementadas por la Corona española con posterioridad a la rebelión de Tupac Amaru y Tupac Catari, lejos de debilitar a la autoridad indígena, fortaleció a las autoridades locales, en algunos casos en desmedro de la figura del cacique. En este sentido, proponemos que los alcaldes que ejercieron autoridad con posterioridad a la rebelión presentan diferencias con los alcaldes mayores de las ordenanzas toledanas. Aquellos, ejercían autoridades sobre extensos territorios, que en muchos casos correspondía a antiguos señoríos o nuevas reducciones que integraban a varios grupos. En cambio los alcaldes de fines del siglo XVIII ejercen poder a nivel de pueblo o doctrina. Al menos eso es lo que se observa en los Altos de Arica.

En este sentido, a nuestro juicio, se manifiesta en las autoridades del cabildo indígena del siglo XVIII el emergente poder político que estaba sustentado en el establecimiento de importantes redes sociales construidas a lo largo de la vida, que incluyeron tanto a otros miembros del cabildo como a sujetos extranjeros a la comunidad, que les valió del prestigio que sustentó su autoridad, manifestado en su participación en bautizos y matrimonios. Es por ello que el liderazgo construido, pese a tener su origen en una disposición administrativa del gobierno colonial, estaría respaldado en una legitimidad social que el cacique ya no podía ostentar, lo que justamente es una de las particularidades del caso de la doctrina de Belén, pues en la mayoría de los estudios sobre el periodo (fines del siglo XVIII) estas autoridades coexisten con los caciques, quienes mantienen mayores o menores grados de legitimidad. Nos parece que el resultado de este proceso potenció la consolidación de organizaciones políticas similares a los sistemas de cargos o a cuerpos colegiados, que pueden observarse en casos como los de Chipaya (Wachtel 2001) y de Tinquipaya (Vicent 2015), respectivamente. 
Por otra parte, la alta frecuencia de diversas autoridades se mantuvo en la doctrina de Belén al menos hasta 1810 , lo que evidencia que el fortalecimiento del cabildo indígena no fue una medida transitoria sino que, por el contrario, coincide con una nueva etapa en la política de las comunidades que caracteriza el fin del periodo Colonial en la región, reflejando la consolidación de un grupo de notables (en palabras de Juan Carlos Garavaglia), lo que evidencia grados de diferenciación social al interior de las comunidades pueblo, pero con una evidente homogeneidad en el nivel de prestigio de estos sujetos de autoridad, y que, por otra parte, no muestran significativas diferencias económicas a nivel de doctrina (salvo escasas excepciones).

Además, ha quedado demostrado que las autoridades locales no sólocumplíanfunciones político-administrativas, sino que también participaban activamente de los ritos religiosos que conformaban la religiosidad local, tanto en su participación en bautizos, matrimonios y entierros, como en su calidad de mayordomos y fabriqueros. Así, el rol que jugaron estas autoridades en distintas instancias del acontecer social del pueblo -como alcaldes, mayordomos, fabriqueros, arrieros, padrinos, testigos, albaceas, cabeza de unidades domésticas, etc-, es lo que sustentó su prestigio, y también su poder. En sus diversas funciones ellos serían quienes produjeron el "régimen de verdad" propuesto por Foucault, es decir, "aquellos encargados de decir qué es lo que funciona como verdadero" (Foucault 1980:187). Evidencia clara de esto se encuentra en el ritual del matrimonio, donde eran consultados como testigos que debían avalar las declaraciones de los contrayentes, previo al matrimonio (Inostroza 2013b).

En cuanto al rol de estas autoridades indígenas en el mundo colonial, algunos investigadores podrían definir a los alcaldes y mayordomos como passeurs culturels (Moro 1997) o mediadores culturales (Ares y Gruzinski 1997). Para nosotros, no lo son. Un mediador cultural es un sujeto que se encuentra en "el medio" de dos realidades, un sujeto mestizo, que presenta características culturales de un tercer estrato social generado de la confluencia de dos mundos distintos (Moro 1997). Por otra parte, el mediador cultural, es decir, el sujeto "móvil" en la sociedad occidental, es un sujeto propio de "los tiempos modernos" (Gruzinski 2005:13); en el sistema andino, por el contrario, la movilidad era parte del sistema socio-económico desde tiempos prehispánico ${ }^{37}$. En esta lógica, si bien los caciques o curacas en muchos casos pueden ser reconocidos como mediadores o passeurs culturels, los sujetos que participaron del sistema de cargos andino, sobre todo alcaldes y mayordomos, sirvieron de conectores sin situarse "al medio de", sino que, por el contrario, moviéndose desde el mundo andino. Es por esto que como agentes históricos corresponden más a sujetos relacionales, desde el punto de vista de Bourdieu (1997), dotados de capital simbólico, o desde el punto de vista de Estermann (1998), como agentes interculturales.

Agradecimientos: Al Proyecto Fondecyt Postdoctoral $n^{\circ}$ 3180287. A los evaluadores anónimos por sus comentarios.

\section{Referencias Citadas}

Albó, X. y M. Mamani 1980. Esposos, suegros y padrinos entre los aymaras. En Parentesco y Matrimonio en los Andes, editado por E. Mayer y R. Bolton, pp. 283-326. Pontificia Universidad Católica del Perú, Lima.

Ares, B. y S. Gruzinski (coord.) 1997. Entre Dos Mundos. Fronteras Culturales y Agentes Mediadores. Escuela de Estudios HispanoAmericanos, Sevilla.

Barriga, V. 1948. Memorias para la Historia de Arequipa. Tomo III. Arequipa.

Boixadós, R. 2008. Caciques y Mandones de Malligasta. Autoridad y memoria en un pueblo de indios de La Rioja Colonial. Andes, Antropología e Historia 19:251-278.

Borgatti, S., M. Everett y L. Freeman 2002. Software for Social Network Analysis. Analytic Technologies, Harvard.

Bourdieu, P. 1997. Razones Prácticas. Sobre la Teoría de la Acción. Anagrama, Barcelona.

Carmagnani, M. 1988. El Regreso de los Dioses: El Proceso de Reconstitución de la Identidad Étnica en Oaxaca, Siglos XVII y XVIII. Fondo de Cultura Económica, México D.F.

Castro, V. 2009. De Ídolos a Santos. Evangelización y Religión Andina en los Andes del Sur. Universidad de Chile, Facultad de Ciencias Sociales. Centro de Investigaciones Diego Barros Arana, Santiago.
Celestino, O. y A. Meyers 1981. Las Cofradías en el Perú: Región Central. Verlag Klaus Dieter Vervuert, Frankfurt/Main.

Chassin, J. 2008. El rol de los alcaldes de indios en las insurrecciones andinas (Perú a inicios del siglo XIX). Bulletin de l'Institut Francais d'Études Andines 37 (1):227-242.

Choque, R. 2003. Jesús de Machaca: La Marka Rebelde. Vol. 1. Cinco Siglos de Historia. Plural, La Paz.

Choque, C. 2015. Los Socoromas. Modos de Vida, Tecnología y Religiosidad. CONADI, Arica.

Cruz, E. 2014. Espacios de aculturación y resistencia indígena al Sur de Charcas. Las cofradías de indios de Jujuy en el siglo XVIII. En Pluralidad Cultural en las Américas, editado por M. Cordero y M. Guevara, pp. 103-130. Editorial Ybris, Sevilla.

Díaz, A., P. Martínez y C. Ponce 2014. Cofradías de Arica y Tarapacá en los siglos XVIII y XIX. Indígenas andinos, sistema de cargos religiosos y festividades. Revista de Indias 74 (260):101-128.

Durston, A. y J. Hidalgo 2004 [1999]. La presencia andina en los valles de Arica, siglos XVI-XVIII: Casos de regeneración colonial de estructuras archipielágicas. En Historia Andina en Chile, editado por J. Hidalgo, pp. 479- 506. Editorial Universitaria, Santiago.

Escobari, L. 2001. Caciques, Yanaconas y Extravagantes. Sociedad y Educación Colonial en Charcas s. XVI-XVIII. Plural/Embajada de España en Bolivia, La Paz. 
Espinoza, W. 1960. El alcalde mayor indígena en el virreinato del Perú. Anuario de Estudios Americanos 17:183-300.

Espinoza, W. 1975. Los mitmas huayacuntu en Quito o guarniciones para la represión armada, siglos XV y XVI. Revista del Museo Nacional XLI:351-394.

Estermann, J. 1998. Filosofía Andina. Estudio Intercultural de la Sabiduría Autóctona Andina. Ediciones Abya-Yala, Quito.

Farberman, J. 2004. Curacas, mandones, alcaldes y curas: legitimidad, autoridad y coerción en los pueblos de indios de Santiago del Estero, siglos XVII y XVIII. Colonial Latin American Historical Review 13 (4):367-397.

Farberman, J. 2008. Santiago del Estero y sus pueblos de indios. De las Ordenanzas de Alfaro (1612) a las guerras de Independencia. Andes, Antropología e Historia 19:225-250.

Farberman, J. y R. Boixadós 2009. Una cartografía del cambio en los pueblos de indios coloniales del Tucumán. Autoridades étnicas, territorialidad y agregaduría en los siglos XVII al XIX. Revista Histórica XLIV:113-146.

Ferreiro, J.P. y F. Fernández 2013. Nupcialidad, compadrazgo y endogamia en las Yungas de Jujuy (Noroeste de Argentina) durante la primera mitad del siglo. Cahiers du Monde Hispanique et Luso-brésilien 101:21-56.

Fernández, F. 2018. Redes de capital social familiar en la región oriental de Jujuy (Argentina) durante las tres primeras décadas del siglo XX. Estudios Atacameños 58:29-48.

Foucault, M. 1980. Verdad y poder. En Microfísica del Poder Edición y traducción de Julia Varela y Fernando Alvarez-Uría, pp. 175-189. Ediciones La Piqueta, Madrid.

Gruzinski, S. 2005. Passeurs y elites 'católicas' en las cuatro partes del mundo. Los inicios ibéricos de la mundialización (1580-1640). En Passeurs, Mediadores Culturales y Agentes de la Primera Globalización en el Mundo Ibérico, Siglo XVI-XIX, editado por S. O'Phelan y C. Salazar-Soler, pp. 13-29. Instituto Francés de Estudios Andinos, Lima.

Hidalgo, J. 1978. Revisita a los Altos de Arica Efectuada por el Oficial Real Don Joaquín de Cárdenas 1750. Universidad del Norte, Arica.

Hidalgo, J. 1986. Indian Society in Arica, Tarapacá and Atacama, 1750-1793, and its Response to the Rebelión of Tupac Amaru. Thesis Ph. D. University of London, London.

Hidalgo, J. 1987. Tierras, exacciones fiscales y mercado en las sociedades de Arica, Tarapacá y Atacama, 1750-1790. La Participación Indígena en los Mercados Surandinos. Estrategias y Reproducción Social. Siglos XVI a XX, compilado por O Harris, B. Larson y E. Tandeter, pp. 193- 231. CERES, La Paz.

Hidalgo, J. 2004 [1987]. Cacicazgos del sur occidental andino: Origen y evolución colonial. En Historia Andina en Chile, editado por J. Hidalgo, pp. 471-477. Editorial Universitaria, Santiago.

Hidalgo, J. 2004 [1996] Rebeliones andinas en Arica, Tarapacá y Atacama, 1770-1781. En Historia Andina en Chile, editado por J. Hidalgo, pp. 247-270. Editorial Universitaria, Santiago.

Hidalgo, J. 2011. Redes eclesiásticas, procesos de extirpación de idolatrías y cultos andinos coloniales en el Corregimiento de Atacama, siglos XVII-XVIII. Estudios Atacameños 42:113-152.

Hidalgo, J., P. Arévalo, M. Marsilli y C. Santoro 1988. Padrón de la Doctrina de Belén en 1813: un Caso de Complementariedad Tardía. Universidad de Tarapacá, Facultad de Estudios Andinos. Departamento de Antropología, Geografía e Historia, Arica.

Hidalgo, J. y N. Castro 2004. El liderazgo étnico en Atacama, Altos de Arica, Tacna y Tarata (siglo XVIII). Chungara Revista de Antropología Chilena 36 (E2):799-811.
Hidalgo, J., N. Castro y S. González 2004. La Revisita de Codpa (Altos de Arica) de 1772-73 efectuada por el corregidor Demetrio Egan. Chungara Revista de Antropología Chilena 36 (1):103-112.

Hidalgo, J. y V. Díaz 1985. Cartas del Obispo de Arequipa sobre los indios del corregimiento de Arica, 1620-1638. Cuatro documentos inéditos. Chungara Revista de Antropología Chilena 15:77-97.

Hidalgo, J., V. Díaz y P. Cisternas 2014. Cartas del Obispo de Arequipa sobre los indios del corregimiento de Arica, 16201638. En Historia Andina en Chile, vol. II. Políticas Imperiales, Dinámicas Regionales y Sociedades Indígenas, editado por J.Hidalgo, pp. 159- 170. Editorial Universitaria, Santiago.

Hidalgo, J. y A. Durston 2004 [1998]. Reconstitución étnica colonial en la sierra de Arica: el cacicazgo de Codpa, 1650-1792. En Historia Andina en Chile, editado por J. Hidalgo, pp. 507-534. Editorial Universitaria, Santiago.

Hidalgo, J., A. Durston, V. Briones y N. Castro 2004 [1997]. El cacicazgo de Tacna: Un proceso de etnogénesis colonial, siglos XVI y XVIII. En Historia Andina en Chile, editado por J. Hidalgo, pp. 535-553. Editorial Universitaria, Santiago.

Hidalgo, J. y X. Inostroza 2019. Dinámicas demográficas de población indígena. Originarios y forasteros en Arica y Tarapacá (1750-1813). Revista Chilena de Antropología 40:255-270.

Hidalgo, J., M. Marsilli y J. Aguilar 2016. Redes familiares, carreras eclesiásticas y extirpación de idolatría: Doctrina de Camiña, Tarapacá. Siglo XVII. Chungara Revista de Antropología Chilena 48 (3):409-428.

Horta, H., J. Hidalgo y L. Figueroa 2016. Transformación y resignificación de la parafernalia alucinógena prehispánica en Atacama a la luz de un documento del siglo XVII. Estudios Atacameños 53:93-116.

Hünefeldt, C. 1982. Luchas por la Tierra y Protesta Indígena: Las Comunidades indígenas del Perú entre Colonia y República. Bonner Americanische Studien, Bonn.

Inostroza, X. 2011. Diferenciación social y liderazgo en comunidades andinas: Los 'Principales' de Belén y Socoroma: 1750-1799. Diálogo Andino 38:35-43.

Inostroza, X. 2013a. Dimensiones del liderazgo étnico en el pueblo de Belén: Francisco Ocharán, secretario del cabildo indígena. Altos de Arica (1750-1813). Estudios Atacameños 46:109-126.

Inostroza, X. 2013b. Políticas matrimoniales y prácticas indígenas. Doctrina de Belén, Altos de Arica (1763-1823). Allpanchis XLI (81-82):245-278.

Inostroza, X. 2014. Matrimonio y familia en sociedades andinas: propuestas desde la reconstitución de familias de Santiago de Tacrama o Belén. Virreinato del Perú (1763-1820). Historia 47 (1):65-90.

Inostroza, X. 2016. Familias y ayllus: alianzas, riqueza y prestigio. Belén 1787 (Altos de Arica). Surandino Monográfico 1:5-22.

Inostroza, X. 2017. Familia y vida cotidiana en poblados indígenas rurales. Cacicazgo de Codpa (1774-1820). Meridional 8:73-96.

Inostroza, X. 2018a. Complementariedad de métodos y fuentes en el estudio histórico de familias indígenas. Belén, Altos de Arica (1750-1820). Estudios Atacameños 58:107-123.

Inostroza, X. 2018b. Evangelización y ritualidad católica en poblados indígenas a fines del período colonial: Parroquia de Belén, Virreinato del Perú (1763-1820). Boletín de la Academia Chilena de la Historia LXXXIV (127):35-65. 
Inostroza, X. 2019. Parroquia de Belén. Población, Familia y Comunidad de una Doctrina Aimara. Altos de Arica, 17631820. Ediciones Biblioteca Nacional, Dirección de Bibliotecas, Archivos y Museos (DIBAM), Santiago.

Inostroza, X., C. Choque, F. Urrutia, J. Hidalgo, M. Uribe y C. Arias 2013. Libros de la Parroquia de Belén. Historia y Memoria. En Coyunturas Pasadas y Presentes de los Pueblos Originarios, coordinado por S. Montecinos, pp. 113-135. Cátedra Indígena, Universidad de Chile, CONADI, Santiago.

Inostroza, X. y J. Hidalgo 2015. Parroquia de Belén: Familias, archivos, memorias. Diálogo Andino 46:95-105.

Isbell, B.J. 1974. Parentesco andino y reciprocidad kuyaq: los que nos aman. En Reciprocidad e Intercambio en los Andes Peruanos, editado por G. Alberti y E. Mayer, pp. 110-152. Instituto de Estudios Peruanos, Lima.

Korsbaek, L. 1995. La historia y la antropología: El sistema de cargos. CIENCIA 2 (2):175-183.

Lavallé, B. 1993. L'Amérique Espagnole de Colomb à Bolivar. Belín, París.

Lohmann Villena, G. 1957. El Corregidor de Indios en el Perú Bajo los Austrias. Instituto de Cultura Hispánica, Madrid.

Marsilli, M. 2014. Hábitos Perniciosos: Religión Andina Colonail en la Diócesis de Arequipa (siglos XVI al XVIII). Dirección de Bibliotecas, Archivos y Museos (DIBAM), Santiago.

Marsilli, M. y P. Cisternas 2010. Los senderos de la idolatría: El viaje de Vázquez de Espinosa por los Altos de Arica, 1618. Chungara Revista de Antropología Chilena 42 (2):465-476.

Marsilli, M. y J. Hidalgo 1992. Hacienda y comunidades andinas en los valles costeros del norte de Chile: Siglos XVIII y XIX. En Comunidades Indígenas y su Entorno, editado por M. Orellana y J.G. Muños, pp. 67-91. Universidad de Santiago de Chile, Santiago.

Marzal, M. 1983. La Transformación Religiosa Peruana. s/e, Lima.

Mayer, E. 1974. Las reglas del juego en la reciprocidad andina. En Reciprocidad e Intercambio en los Andes Peruanos, editado por G. Alberti y E. Mayer, pp. 37-65. Instituto de Estudios Peruanos, Lima.

Mendinacelli, X. y M. Inch (coord.) 2010. Pleitos y Riqueza. Los Caciques Andinos en Potosí del Siglo XVII. Transcripción y Estudios del Expediente de don Diego Chambilla contra los Bienes de su Administrador. Ediciones Archivo y Biblioteca Nacionales de Bolivia, Sucre.

Mendoza, E. 2011. Municipios, Cofradías y Tierras Comunales. Los Pueblos Chocholtecos de Oaxaca en el Siglo XIX. Universidad Autónoma Metropolitana, Oaxaca.

Millones, L. 1978. Religión y poder en los Andes: los Curacas idólatras de la Sierra Central. En Etnohistoria y Antropología Andina. Primera Jornada del Museo Nacional de Historia, editado por A. Castelli y M. Koth, pp. 253-273. Museo Nacional de Historia, Lima.

Millones, L. 1979. Los ganados del señor: Mecanismos de poder en las comunidades andinas, siglos XVIII y XIX. América Indígena 39 (1):107-45.

Millones, L. 1984. Shamanismo y política en el Perú colonial: Los curacas de Ayacucho. Histórica III (2):131-148.

Mintz, S. y E. Wolf 1950. An analysis of ritual co-parenthood (compadrazgo). Southwestern Journal of Anthropology 6 (4):341-368.

Montes del Castillo, A. 1989. Simbolismo y Poder: Un Estudio Antropológico Sobre Compadrazgo y Priostazgo en una Comunidad Andina. Anthropos Editorial, Barcelona.

Moro, R. 1997. Mobilità e 'Passeurs culturels': Il caso dell' America colonial espagnola. En Entre Dos Mundos. Fronteras Culturales y
Agentes Mediadores, coordinado por B. Ares y S. Gruzinski, pp. 149-174. Escuela de Estudios Hispano-Americanos, Sevilla.

Morrone, A. 2016. No todos los caciques fueron Mallku. Mediación política truncada en los corregimientos de Pacajes y Omasuyos (Audiencia de Charcas, 1570-1630). Diálogo Andino 50:207-217.

Murra, J. 1975. Formaciones Económicas y Políticas del Mundo Andino. Instituto de Estudios Peruanos, Lima.

Núñez, L. 1996. Movilidad caravánica en el área centro-sur andina: reflexiones y expectativas. En La Integración Surandina. Cinco Siglos Después, compilado por X. Albó, A. Arriatia, J. Hidalgo, L. Núñez, A. Llagostera, M. I. Remy, B. Revesz, pp. 43-63. Centro de Estudios Regionales Andinos Bartolomé de Las Casas, Corporación Norte Grande Taller de Estudios Andinos, Universidad Católica del Norte de Antofagasta, Cusco.

Núñez, L. y V. Castro 2011. ¡Caitunar, Caitunar!: Pervivencia de ritos de fertilidad prehispánica en la clandestinidad del Loa (Norte de Chile). Estudios Atacameños 42:153-172.

O’ Phelan, S. 1977. El norte y los movimientos antifiscales del siglo XVIII. Histórica 2 (1):199-222.

O' Phelan, S. 1988. Un Siglo de Rebeliones Anticoloniales. Perú y Bolivia 1700-1783. Centro de Estudios Regionales Andinos Bartolomé de Las Casas, Cusco.

O' Phelan, S. 1992. Rebeliones andinas anticoloniales. Nueva Granada, Perú y Charcas entre el siglo XVIII y XIX. Anuario de Estudios Americanos XLIX:395-440.

O’ Phelan, S. 1997. Kurakas Sin Sucesiones: del Cacique al Alcalde de Indios (Perú y Bolivia 1750-1835). Centro de Estudios Regionales Andinos Bartolomé de Las Casas, Cusco.

O'Phelan, S. 2013. Mestizos Reales en el Virreinato del Perú: Indios Nobles, Caciques y Capitanes de Mita. Fondo Editorial del Congreso del Perú, Lima.

Palacios, J. y R. Díaz 2013. Las cofradías de indígenas en el Santiago colonial: estrategias para la construcción de una identidad musical. Revista de Estudios Colombinos 9:77-86.

Palomeque, S. 1998. El sistema de autoridades de "pueblos de indios" y sus transformaciones a fines del período colonial. El Partido de Cuenca. En Dos Décadas de Investigación en Historia Económica Comparada en América Latina. Homenaje a Carlos Sempat Assadourian, coordinado por M. Menegus. El Colegio de México/I.Mora/CIESAS/ CESU/UNAM, México D.F.

Palomeque, S. 2000. La "ciudadanía" y el sistema de gobierno en los pueblos de Cuenca. Cuadernos de Historia Latinoamericana AHILA 8:115-139.

Palomeque, S. 2006. La 'historia' de los señores étnicos de Casabindo y Cochinoca (1540-1662). Andes 17:139-194.

Pease, F. 1992. Curacas, Reciprocidad y Riqueza. Pontificia Universidad Católica del Perú, Fondo Editorial, Lima.

Peralta, V. 1991. En Pos del Tributo. Burocracia Estatal, Élite Regional y Comunidades Indígenas en el Cusco Rural (1826-1854). Centro de Estudios Regionales Andinos Bartolomé de las Casas, Cusco.

Pereira, M. 2013. La evangelización en la Ruta de La Plata, Arica y Parinacota. Espacio Regional 1 (10):31-44.

Platt, T. 1987. The Andean Soldiers of Christ. Confraternity organization, the mass of the sun and regenerative warfare in rural Potosi (18th-20th centuries). Journal de la Société Des Américanistes 73:139-191 
Platt, T., T. Bouysee-Cassagne y O. Harris 2006. Qaraqara-Charka. Mallku, Inka y Rey en la Provincial de Charcas (siglos XV-XVII). Historia Antropológica de una Confederación Aymara. Instituto Francés de Estudios Andinos, Lima.

Rivera Cusicanqui, S. 1978. El mallku y la sociedad colonial en el siglo XVII: El caso de J. de Machaca. Avances 1:7-27.

Ríos, W. 1990. Continuidad y permanencia de mecanismos de colaboración, solidaridad y participación en la I Región Tarapacá. Diálogo Andino 9:49-57.

Rodríguez, L. 2017. Cuyo nombramiento no lo obtuvo sino por su buena conducta pues nunca fue indio de aquel pueblo. Caciques y alcaldes en el pueblo de Colalao y Tolombón entre la colonia y la república. Tzintzun. Revista de Estudios Históricos 66:11-36.

Saignes, T. 1987. De la borrachera al retrato. Los caciques andinos entre dos legitimidades (Charcas). Revista Andina 5 (1):139-170.

Sala i Vila, N. 1993. La constitución de Cádiz y su impacto en el gobierno de las comunidades indígenas en el Virreinato del Perú. Boletín Americanista 42-43:51-71.

Sala i Vila, N. 1996. Y se Armó el Tole Tole. Tributo Indígena y Movimientos Sociales en el Virreinato del Perú. 1784-1814. IER José María Arguedas, Ayacucho.

Salomon, F. 1987. Ancestor Cults and Resistance to the State in Arequipa, ca. 1748-1754. En Resistance, Rebellion and Consciousness in the Andean Peasant World 18th to 20th Centuries, editado por S.J. Stern, pp. 148-165. The University of Wisconsin Press, Madison.

Serulnikov, S. 2006. Conflictos Sociales e Insurrección en el Mundo Colonial Andino. El Norte de Potosí en el Siglo XVIII. Fondo de Cultura Económica, México D.F.

Spalding, K. 1974. De Indio a Campesino: Cambios en la Estructura del Perú Colonial. Instituto de Estudios Peruanos, Lima.

Spalding, K. 1984. Huarochirí. An Andean Society Under Inca and Spanish Rule. University Press, Stanford

Thomson, S. 2006. Cuando Sólo Reinasen los Indios. La Política Aymara en la Era de la Insurgencia. Muela del Diablo EditoresAruwiyiri, La Paz.

Topete, H. 2014. Los gobiernos locales, los cargos civiles y los cargos religiosos en las recientes etnografías en el Estado de Oaxaca, México. Diálogo Andino 43:9-16.

Trellez, E. 1982. Lucas Martínez Vegazo: Funcionamiento de Una Encomienda Peruana Inicial. Pontificia Universidad Católica del Perú, Lima.

Valenzuela, J. 2010. Devociones de inmigrantes. Indígenas andinos y plurietnicidad urbana en la conformación de cofradías coloniales (Santiago de Chile, siglo XVII). Historia 43 (1):203-244.

Van Kessel, J. 1989. La Iglesia Católica Entre los Aymaras. Rehue, Santiago.

Vargas Ugarte, R. 1951. Concilios Limenses (1551-1772). Lima.

Vicent, N. 2015. Los Ayllus de Tinquipaya. Ensayos de Historia a Varias Voces. Plural, La Paz.

Wachtel, N. 1973. Sociedad e Ideología. Ensayos de Historia y Antropología Andinas. Instituto de Estudios Peruanos, Lima.

Wachtel, N. 1976. Los Vencidos. Los Indios del Perú Frente a la Conquista Española (1530-1570). Alianza Editorial, Madrid.
Wachtel, N. 2001, El Regreso de los Antepasados. Los Indios Urus de Bolivia, del Siglo XX al XVI. Ensayo de Historia Regresiva. Fondo de Cultura Económica, México D.F.

Walker, Ch. 2013. De Tupac Amaru a Gamarra: Cuzco y la Formación del Perú Republicano (1780-1840). Centro de Estudios Regionales Andinos Bartolomé de las Casas, Cusco.

Vergara, T. 2015. Piedad barroca e interés económico: la cofradía de Crispín y Crispiniano de los zapateros indígenas de Lima (16341637). En Iglesia y Sociedad en la Nueva España y el Perú, editado por A. Mayer y J. De la Puente, pp. 151-171. Pontificia Universidad Católica del Perú- Instituto Riva-Agüero, Lima.

Wolf, E. 1959. Pueblos y Culturas de Mesoamérica. Ediciones ERA, México D.F.

Wolf, E. 1980. Relaciones de parentesco, de amistad y de patronazgo en las sociedades complejas. En Antropología Social de las Sociedades Complejas, editado por M. Banton, pp. 19-39. Alianza Editorial, Madrid.

Yannakakis, Y. 2012. El Arte de Estar en Medio. Intermediarios Indígenas, Identidad India y Régimen Local en la Oaxaca Colonial. UABJO-El Colegio de Michoacán, México D.F.

Zanolli, C. y C. Alonso 2004. Santa Bárbara, una cofradía de indios en San Antonio de Humahuaca (1713-1785). Anuario de Historia Regional y de las Fronteras 9 (1):87-109.

Zanolli, C. 2008. Entre la coerción, la oportunidad y la salvación Las cofradías de indios de San Antonio de Humahuaca. Siglos XVII y XVIII. Andes 19: 345-367.

Zuloaga, M. 2012. La Conquista Negociada: Guarangas, Autoridades Locales e Imperio en Huaylas, Perú (1532-1610). Instituto Francés de Estudios Andinos, Instituto de Estudios Peruanos, Lima.

\section{Siglas}

AAA Archivo Arzobispal de Arequipa.

AN Archivo Nacional

AHLMRREEP Archivo Histórico de Límites, Ministerio de Relaciones Exteriores del Perú.

PB Fondo Parroquia de Belén.

JA Judiciales Arica

\section{Documentos de Archivo}

AAA. Belén. Confirmaciones de 1794. Arica-Belén. 1694-1856.

AAA. Demarcación y lista de contribuyentes de la Doctrina de Belén. 1787. Arica-Belén. 1694-1856.

AAA. Cuentas de cofradía. Tocoroma-Arica. 1669-1714. Arica, 1630-1895.

AAA. Cuentas e inventario de Socoroma. 1681-1877. Arica-Belén. 1694-1856.

AAA. Cofradía. 10/12/1677-16/11/1793. Arica-Codpa. 1650-1891.

AAA. Expediente administrativo, 1748. Arica-Codpa 1650-1891.

AAA. Vicaría de Arica. Cuentas. 27 de agosto 1718-18 de julio 1787. Arica. 1630-1895.

AHLMRREEP. Inventario que se hacen de las Iglesias de Belén, Socoroma, Putre y Pachama. 1778-1837. ARI-1; caja 416.

AN. Fondo Parroquia de Belén. Vol. 1 al 11.

AN JA. Prudencio Condori contra Lucas San Martín. 1796. Legajo 38, Pieza 5. 


\section{Notas}

1 AAA. Expediente Administrativo, 1748. Arica-Codpa. 1650-1891.

${ }^{2}$ Celestino y Meyers (1981) proponen el establecimiento de una relación entre cofradías y ayllus en el contexto del Perú Central, y la función que tuvieron para grupos privilegiados. Otros estudios sobre cofradías indígenas en Cruz 2014, Martínez y Díaz 2019, Palacios y Díaz 2013, Valenzuela 2010, Vergara 2015, Wachtel 2001, Zanolli 2008, Zanolli y Alonso 2004, entre otros.

3 AN JA. Prudencio Condori contra Lucas San Martín, 1796. Legajo 38, Pieza 5.

${ }^{4}$ Hemos abordado distintos aspectos sobre la doctrina de Belén y el cacicazgo de Codpa en trabajos anteriores, que están en las referencias bibliográficas. Se pueden consultar además Inostroza e Hidalgo 2015, Inostroza et a. 2013, Inostroza 2014, Inostroza 2017, Inostroza 2018a

${ }^{5}$ La mayor parte de ella proveniente del Archivo Arzobispal de Arequipa.

${ }^{6}$ AN PB Vol. IV, f. 48. Según Palomeque, en el caso de Cuenca el cargo de gobernador o cacique gobernador no era electivo sino designado por la audiencia a propuesta del corregidor, que tenía la jurisdicción criminal y civil por delitos leves, junto con el alcalde (Palomeque 1998).

${ }^{7} \mathrm{El}$ proceso descrito se puede equiparar al de reconstitución étnica que identificó Carmagnani en Oaxaca entre fines del siglo XVII y principios del XIX, sobre todo en la generación de una diversificación social interna (1988).

${ }^{8}$ Categoría tributaria. Ver Inostroza 2019, Hidalgo e Inostroza 2019.

9 AHLMRREEP. Inventario que se hacen de las Iglesias de Belén, Socoroma, Putre y Pachama. 1778-1837. ARI-1; caja 416.

${ }^{10}$ AAA. Vicaría de Arica. Cuentas. 27 de agosto 1718-18 de julio 1787. Arica. 1630-1895.

${ }^{11}$ AHLMRREEP. Inventario que se hacen de las Iglesias de Belén, Socoroma, Putre y Pachama. 1778-1837. ARI-1; caja 416.

${ }^{12}$ AHLMRREEP. Inventario que se hacen de las Iglesias de Belén, Socoroma, Putre y Pachama. 1778-1837. ARI-1; caja 416.; AAA. Vicaría de Arica. Cuentas. 27 de agosto 1718-18 de julio 1787. Arica. 1630-1895.

${ }^{13}$ AAA. Demarcación y lista de contribuyentes de la Doctrina de Belén. 1787. Arica-Belén. 1694-1856. El documento no indica la cofradía de los dos mayordomos, pero se ha identificado al otro mayordomo en la cofradía de Nuestra Santísima Concepción.

${ }^{14}$ AHLMRREEP. Inventario que se hacen de las Iglesias de Belén, Socoroma, Putre y Pachama. 1778-1837. ARI-1; caja 416.

${ }^{15}$ AN PB. Vol. VII, f. 77v, 82v.

${ }^{16}$ AHLMRREEP. Inventario que se hacen de las Iglesias de Belén, Socoroma, Putre y Pachama. 1778-1837. ARI-1; caja 416.

${ }^{17}$ AHLMRREEP. Inventario que se hacen de las Iglesias de Belén, Socoroma, Putre y Pachama. 1778-1837. ARI-1; caja 416.

${ }^{18}$ AAA. Vicaría de Arica. Cuentas. 27 de agosto 1718-18 de julio 1787. Arica. 1630-1895.

${ }^{19}$ AHLMRREEP. Inventario que se hacen de las Iglesias de Belén, Socoroma, Putre y Pachama. 1778-1837. ARI-1; caja 416.
${ }^{20}$ AHLMRREEP. Inventario que se hacen de las Iglesias de Belén, Socoroma, Putre y Pachama. 1778-1837. ARI-1; caja 416.

${ }^{21}$ AAA. Cuentas e inventario de Socoroma. 1681-1877. Arica-Belén. 1694-1856.

${ }^{22}$ AAA. Cuentas de cofradía. Tocoroma-Arica, 1669-1714. Arica, 1630-1895.

${ }^{23}$ Algunos investigadores proponen la desaparición de la cofradía y la permanencia de un sistema de cargos. Véase Díaz et al. 2014.

24 "In San Marcos de Miraflores, we might therefore expect to find each confraternity organized by turns among the scattered membres of a single ayllu, since territorial cohesion is conspicuously absent from the valley residence pattern. In fact, there is an alternative solution which makes each confraternity largely dependent on a system of turns among the members of different moieties and ayllus" (Platt 1987:147).

${ }^{25}$ AHLMRREEP. Inventario que se hacen de las Iglesias de Belén, Socoroma, Putre y Pachama. 1778-1837. ARI-1; caja 416. Otros aspectos de la vida de Tomás Marca en Inostroza 2013b.

${ }^{26}$ AHLMRREEP. Inventario que se hacen de las Iglesias de Belén, Socoroma, Putre y Pachama. 1778-1837. ARI-1; caja 416.

${ }^{27}$ AHLMRREEP. Inventario que se hacen de las Iglesias de Belén, Socoroma, Putre y Pachama. 1778-1837. ARI-1; caja 416.

${ }^{28}$ AAA. Cofradía. 10/12/1677-16/11/1793. Arica-Codpa. 16501891.

${ }^{29}$ AHLMRREEP. Inventario que se hacen de las Iglesias de Belén, Socoroma, Putre y Pachama. 1778-1837. ARI-1; caja 416.

${ }^{30}$ AN PB. Vol V, f. 84.

${ }^{31}$ Lo mismo en Pereira 2013 y en Díaz et al. 2014. Sobre el sistema de cargos actual en Socoroma y las funciones de cada cargo véase Choque 2015.

${ }^{32}$ La bibliografía sobre compadrazgo es extensa. Destacamos los trabajos de Wolf 1980, Montes del Castillo 1989, Isbell 1974, Ferreiro y Fernández 2013, Fernández 2018, entre muchos otros.

${ }^{33}$ Se refieren al Corregimiento de Carangas, Obispado de Charcas.

${ }^{34} \mathrm{Se}$ analiza el testamento de Francisco Ocharán en Inostroza 2013a. Sobre asimetría y verticalidad en el compadrazgo aymara ver sobre todo Albó y Mamani 1980.

${ }^{35}$ En el Archivo Arzobispal de Arequipa se encuentra una lista de confirmaciones que indican ahijado y padrino, sin embargo, corresponde a la confirmación realizada exclusivamente el 10 de julio de 1794 por lo que decidimos no incluir esas relaciones en las redes sociales. AAA. Belén. Confirmaciones de 1794. Arica-Belén. 1694-1856.

${ }^{36}$ Ver por ejemplo Isbell 1974, Ríos 1990.

37 "La existencia de un sistema de transporte andino (indígena) representa una variable significativa respecto de la realidad mesoamericana donde domina el sistema de origen español" (Moro 1997:163). La bibliografía respecto de la movilidad andina es extensa. La propuesta de Lautaro Núñez es particularmente significativa (Núñez 1996). 
